\title{
Stress-Induced Grain Growth in an Ultra-Fine Grained Al Alloy
}

\author{
YAOJUN LIN, HAIMING WEN, YING LI, BIN WEN, WEI LIU, \\ and ENRIQUE J. LAVERNIA
}

ENRIQUE J. LAVERNIA

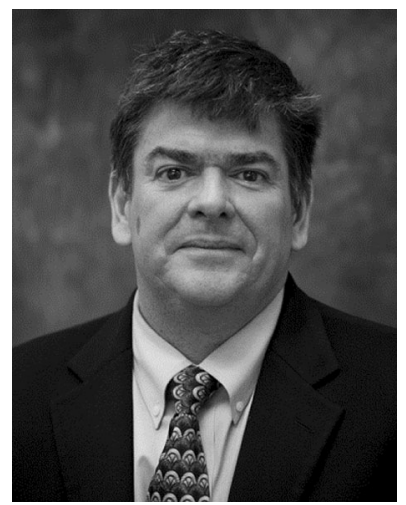

\begin{abstract}
This paper reports on a study of the stress-induced grain growth phenomenon in the presence of second-phase particles and solutes segregated at grain boundaries (GBs) during high-temperature deformation of an ultra-fine grained (UFG) Al alloy synthesized via the consolidation of mechanically milled powders. Our results show that grain growth was essentially inhibited during annealing at $673 \mathrm{~K}\left(400{ }^{\circ} \mathrm{C}\right)$ in the absence of an externally applied stress, whereas in contrast, grain growth was enhanced by a factor of approximately 2.7 during extrusion at $673 \mathrm{~K}\left(400{ }^{\circ} \mathrm{C}\right)$. These results suggest that significant grain growth during hot extrusion was attributable to the externally applied stresses stemming from the state of stress imposed during extrusion and that the externally applied stresses can overcome the resistance forces generated by second-phase particles and solutes segregated at GBs. The mechanisms underlying stress-induced grain growth were identified as GB migration and grain rotation, which were accompanied by dynamic recovery and possible geometric dynamic recrystallization, while discontinuous dynamic recrystallization did not appear to be operative.
\end{abstract}

DOI: $10.1007 / \mathrm{s} 11663-014-0049-4$

(C) The Minerals, Metals \& Materials Society and ASM International 2014

YAOJUN LIN, formerly Postdoctoral Scholar with the Department of Chemical Engineering and Materials Science, University of California, Davis, CA 95616, is now Professor with State Key Laboratory of Metastable Materials Science and Technology and College of Materials Science and Engineering, Yanshan University, Qinhuangdao, Hebei 066004, P.R. China. Contact e-mail: yjlin@ysu.edu.cn HAIMING WEN, Postdoctoral Scholar, is with the Department of Chemical Engineering and Materials Science, University of California. YING LI, formerly Postdoctoral Researcher with the Department of Chemical Engineering and Materials Science, University of California, is now Engineer-Process with Micron Technology, Boise, ID 83707. BIN WEN, Professor, is with State Key Laboratory of Metastable Materials Science and Technology and College of Materials Science and Engineering, Yanshan University. WEI LIU, Professor, is with Nano Structural Materials Center, School of Materials Science and Engineering, Nanjing University of Science and Technology, Nanjing, Jiangsu 210009, P.R. China. ENRIQUE J. LAVERNIA, Professor, is with the Department of Chemical Engineering and Materials Science, University of California. Contact e-mail: lavernia@ucdavis.edu

Manuscript submitted February 4, 2014

Article published online March 25, 2014.

Enrique J. Lavernia earned both his Ph.D. in materials engineering and his M.S. in metallurgy from Massachusetts Institute of Technology; he earned his B.S. with honors in solid mechanics from Brown University. His research interests include the synthesis and behavior of nanostructured and multi-scale materials with particular emphasis on processing fundamentals and physical behavior; thermal spray processing of nanostructured materials; spray atomization and deposition of structural materials; high temperature-high pressure atomization processes; mathematical modeling of advanced materials and processes; and additive manufacturing. He has published 515 journal and 225 conference publications on topics ranging from nanomaterials to extremely strong aluminum alloys. Prof. Lavernia has delivered more than 150 invited lectures and seminars in over 17 countries. He is the Editor-in-Chief of Materials Science and Engineering A, an international journal, and serves on the board of review for various journals including Metall. Mater. Trans. A, Metall. Mater. Trans. B, and Reviews on Advanced Materials Science, in addition to service on international advisory committees of various technical conferences and meetings.

Prof. Lavernia is a Fellow of the Minerals, Metals \& Materials Society (TMS), ASM International, Materials Research Society (MRS), the American Society of Mechanical Engineering (ASME), and the American Association for the Advancement of Science (AAAS). In 2011 Prof. Lavernia received the Hispanic Engineer National Achievement Award (HEENAC) from Great Minds in STEM, and the Distinguished Scientist 


\section{INTRODUCTION}

STRESS-INDUCED grain growth has attracted considerable interest among the scientific community as evidenced by the number of articles published during the past decade. ${ }^{[1-24]}$ These research efforts have been motivated primarily by two factors: scientific interest and technological importance. From a scientific perspective, it is of interest to provide insight into the fundamental mechanisms that are active during stress-induced grain growth, including the role of any externally applied stresses, as well as the interactions between those mechanisms, for example. From a technological standpoint, understanding these fundamental questions is a prerequisite in order to be able to control grain size which critically influences mechanical behavior, since the manufacturing of the vast majority of materials involves some type of plastic deformation processing and the presence of externally applied stresses which are likely to influence grain growth phenomena. For example, most industrial products are fabricated via conventional plastic deformation approaches (e.g., rolling, forging, and extrusion), ${ }^{[25,26]}$ and more recently, nanostructured (NS) and ultra-fine grained (UFG) metals are frequently synthesized either via severe plastic deformation approaches (equal-channel angular pressing, ${ }^{[27]}$ high-pressure torsion, ${ }^{[28]}$ accumulative rolling bonding, ${ }^{[29]}$ etc.) or by consolidation of NS powders, ${ }^{[30]}$ during which the aforementioned conventional plastic deformation approaches are implemented for secondary consolidation.

Recent studies on stress-induced grain growth involve in situ ${ }^{[1-8]}$ and ex situ ${ }^{[9-13]}$ transmission electron microscopy (TEM) analysis, optical microscopy observations ${ }^{[14,15]}$, and molecular dynamic (MD) simulations. ${ }^{[16-24]}$ Related published theoretical and experimental results reveal that there are two roles that an externally applied stress plays during grain growth: (1) provides a driving force for grain growth, ${ }^{[2,16]}$ and (2) promotes the coupling between the two mechanisms responsible for grain growth, including grain boundary (GB) migration and grain rotation. ${ }^{[2,7,14,18,20,21,24,31]}$ Noteworthy, however, is the fact that most published theoretical and experimental papers related to stress-induced grain growth focus on single-phase materials and as a result, material systems containing second-phase particles have been rarely reported. Moreover, although many materials that contain a high level of solute segregation at GBs are selected as model materials for studies of stress-induced grain growth ${ }^{[5,9,11,32,33]}$ the influence of solute atoms segregated at GBs on stressinduced grain growth has been investigated only in very limited cases. ${ }^{[24,34]}$ For example, in a related study, ${ }^{[34]}$ the effect of $\mathrm{O}$ segregated at GBs in nanocrystalline $\mathrm{Al}$ films produced by magnetron sputtering on stress-induced grain

Award from Society for the Advancement of Chicanos and Native Americans in Science (SACNAS). He is also the recipient of the ASM International 2013 Gold Medal Award and presented the ASM 2013 Edward DeMille Campbell Memorial Lectureship. He was the 2005 recipient of the Outstanding Engineering Alumnus Medal from Brown University. In 2013, Prof. Lavernia was elected to the National Academy of Engineering "for contributions to novel processing of metals and alloys, and for leadership in engineering education." growth during uniaxial tensile testing was investigated via TEM and atom-probe tomography (APT). The results of this study revealed that segregated $\mathrm{O}$ could inhibit stressinduced grain growth as a consequence of pinning of GBs by segregated $\mathrm{O}$ when the concentration of segregated $\mathrm{O}$ exceeds a critical level; these results were subsequently validated on the basis of MD simulations. ${ }^{[24]}$ Interestingly, the MD results ${ }^{[24]}$ suggest that the critical stress required for triggering coupled GB motion can be expressed as a function of $\mathrm{O}$ concentration at the GB.

Furthermore, published experimental studies of stressinduced grain growth predominantly address phenomena that occur at room temperature (RT) ${ }^{[1,3-7,9,11-13]}$ and cryogenic temperature. ${ }^{[10]}$ In contrast, stress-induced grain growth at elevated temperatures has been investigated only in few studies, ${ }^{[2,8]}$ which hinders our basic understanding of the aforementioned commercially important plastic deformation approaches, including extrusion, rolling, forging, etc. These plastic deformation processes generally involve elevated temperatures and are widely used, not only in industrial production, but also for the synthesis of NS and UFG materials via the consolidation of NS powders, as presented above. These deformation processes result in stress-induced grain growth being accompanied by dynamic recovery (DRV) and/or dynamic recrystallization (DRX), which increase their complexity. Significantly, despite the fact that experimental results ${ }^{[2,8]}$ as well as MD simulations ${ }^{[16-18,21]}$ show that stress-induced grain growth is indeed present at elevated temperatures, the interactions between stress-induced grain growth and possible DRV and/or DRX have heretofore not been studied in detail.

On the basis of the above discussion, the present study was motivated by two factors. First, there is a lack of fundamental information on stress-induced grain growth in the presence of both second-phase particles and solute atoms segregated at GBs, which hinders our ability to effectively control grain size evolution in many technically important alloys (e.g., A1 alloys, steels, etc.). Second, published experimental studies on stress-induced grain growth phenomena during high-temperature plastic deformation processes are very limited, ${ }^{[2,8]}$ which limit our knowledge of the conditions required to carefully control the behavior of NS and UFG metals during consolidation as well as of engineering materials during thermomechanical processing. In the present study, stress-induced grain growth occurring in an UFG 5083Al (an Al-Mg-Mn$\mathrm{Cr}$ alloy) during hot extrusion at $673 \mathrm{~K}\left(400{ }^{\circ} \mathrm{C}\right)$ was first analyzed and discussed by comparing the scenarios of grain growth in the absence and presence of an externally applied stress, and the mechanisms governing stress-induced grain growth, including GB migration and grain rotation, were then identified based on microstructural analysis.

\section{EXPERIMENTAL PROCEDURES}

The model material 5083Al selected for study was synthesized via the consolidation of mechanically milled 
powders, using the following procedure. First, as-atomized $5083 \mathrm{Al}$ pre-alloyed powders of less than $40 \mu \mathrm{m}$ in diameter that contain supersaturated solution of constituent elements $\mathrm{Mg}, \mathrm{Mn}$, and $\mathrm{Cr}$ were used as starting powders. Second, the gas-atomized powders were mechanically milled using stainless steel balls and a vessel in an argon atmosphere at RT for 4 hours. Third, the mechanically milled powders were then canned, degassed at $673 \mathrm{~K}\left(400{ }^{\circ} \mathrm{C}\right)$ for 25 hours, and consolidated via hot isostatic pressing (HIPping) under $175 \mathrm{MPa}$ at $648 \mathrm{~K}\left(375^{\circ} \mathrm{C}\right)$ for 4 hours to prepare fully dense materials. The composition of the as-hot isostatic pressed (HIPped) 5083Al was measured using chemical analysis conducted at a commercial laboratory (Luvak Inc., Boylston, MA) per ASTM E1097-07, E1019-08, and E1447-09 and is given in Table I. The impurities C, $\mathrm{O}, \mathrm{N}, \mathrm{Fe}, \mathrm{Ni}, \mathrm{Si}$, and $\mathrm{Cu}$ either originated from the raw materials used or were introduced during milling.

The grain growth phenomenon in the as-HIPped 5083 Al was then investigated for the following two cases: i) annealing at $673 \mathrm{~K}\left(400{ }^{\circ} \mathrm{C}\right)$ for 5 hours in the absence of an applied stress, and ii) extrusion at $673 \mathrm{~K}\left(400{ }^{\circ} \mathrm{C}\right)$ with an area reduction ratio of 10 (true strain 2.30 ) under a ram speed of $1.4 \mathrm{~mm} / \mathrm{s}$. The extruded material was prepared as follows. First, prior to extrusion, the as-HIPped $5083 \mathrm{Al}$ round billet of $25 \mathrm{~mm}$ in diameter and $50 \mathrm{~mm}$ in length was held at $673 \mathrm{~K}\left(400{ }^{\circ} \mathrm{C}\right)$ for 1 hour. Second, the preheated round billet was extruded using a die of $8.6 \mathrm{~mm}$ in the length of the deformation zone. Third, a round rod of $7.9 \mathrm{~mm}$ in diameter was produced following extrusion. We estimated that the extrusion process lasted $\sim 36$ seconds, with an associated deformation time of $\sim 2.9$ seconds and a strain rate of $\sim 0.8 \mathrm{~s}^{-1}$ on the basis of the extrusion die geometry and the extrusion parameters used in the present study. Following annealing and extrusion, the materials were immediately water quenched to suppress any possible microstructural evolution.

The microstructures of as-HIPped, annealed, and extruded 5083 Al were investigated using TEM Philips CM 12 and high-resolution TEM (HRTEM) JEOL JEM 2500 SE operated at voltages of 120 and $200 \mathrm{kV}$, respectively. The grain size (d) and the second-phase particle size $(l)$ are represented by an area-equivalent circle diameter; in TEM bright-field (BF) images, crosssectional areas of the grains $\left(S_{\mathrm{g}}\right)$ and of the secondphase particles $\left(S_{\mathrm{p}}\right)$ were measured and converted to area-equivalent circle diameters using the following equations: $d=\left(4 S_{\mathrm{g}} / \pi\right)^{1 / 2}$ and $l=\left(4 S_{\mathrm{p}} / \pi\right)^{1 / 2}$. On the basis of a large number of randomly selected TEM BF images, the statistical distributions of grain sizes and second-phase particle sizes were determined and their average values were calculated by fitting the statistical distributions using lognormal probability function. ${ }^{[34-36]}$ The preparation of TEM and HRTEM specimens is described as follows. First, the materials were sectioned, mechanically thinned to $<30 \mu \mathrm{m}$, and dimpled (VCR D500i dimpler) to 10 to $20 \mu \mathrm{m}$ in thickness. For the extruded $5083 \mathrm{Al}$, the materials were taken along the extrusion direction and thinned perpendicular to the extrusion direction. Then, the materials were further thinned to an electron-transparent thickness using a Gatan PIPS 691 precision ion milling system under an $\mathrm{Ar}^{+}$accelerating voltage of $4 \mathrm{kV}$. X-ray diffraction (XRD) analysis was also conducted on as-milled 5083 Al powders, as-HIPped, and extruded $5083 \mathrm{Al}$ bulk materials using Scintag XDS2000 X-ray diffractometer that is equipped with a $\mathrm{Cu}$ target operated at $1.8 \mathrm{~kW}$.

For the extruded $5083 \mathrm{Al}$, the solute concentrations at GBs and at grain interiors (GIs) were measured via a Cameca local-electrode atom-probe (LEAP) 4000X-Si tomograph with a pulsed ultra-violet laser $(355 \mathrm{~nm}$ wavelength), a pulse repetition rate of $500 \mathrm{kHz}$, and a pulse energy of 10 to $15 \mathrm{pJ}$. Steady-state direct-current voltages between 2.0 and $8.0 \mathrm{kV}$ were applied, with the specimen base temperature being $30 \mathrm{~K}\left(-243{ }^{\circ} \mathrm{C}\right)$. Nine datasets were collected and analyzed by three-dimensional (3D) reconstruction and visualization using Cameca's software program IVAS version 3.6.4. The specimens for APT analysis were prepared by sectioning rectangular cuboids with dimensions of $\sim 10 \mathrm{~mm} \times \sim 0.3 \mathrm{~mm} \times \sim 0.3 \mathrm{~mm}$ from the bulk materials and then electropolishing the rectangular cuboids to needle-shaped tips with a diameter of $\sim 50 \mathrm{~nm}$ at the apex using 10 pct perchloric acid in acetic acid and 2 pct perchloric acid in butoxyethanol as the electrolytes.

\section{RESULTS}

\section{A. Microstructure of the as-HIPped $5083 \mathrm{Al}$}

The typical TEM microstructure of the as-HIPped 5083 $\mathrm{Al}$ is shown in Figure 1(a), and it shows reasonably equiaxed ultra-fine grains. HRTEM analysis revealed that more than 85 pct of these grains are separated by HAGBs (misorientation $>15 \mathrm{deg}$ ). A representative HRTEM image containing a GB is displayed in Figure 1(b), where grain A shows a clear two-dimensional atomic image as a result of being on $\langle 110\rangle$ zone axis, while in contrast, the neighboring grain $\mathrm{B}$ exhibits an amorphous-like characteristics, indicative of an orientation far away from the zone axes. The difference in the HRTEM feature between grains A and B suggests that their GB is of high-angle nature. The above result is consistent with the conclusion in the published studies on UFG Al alloys synthesized via consolidation of mechanically milled NS powders. ${ }^{[37,38]}$ The grain size distribution was obtained based on measurements on 302 grains randomly selected, as shown in Figure 1(c); the average grain size was determined to be $\bar{d}=244 \mathrm{~nm}$.

Table I. Chemical Composition of the as-HIPped 5083Al (Wt Pct)

\begin{tabular}{cccccccccccc}
\hline $\mathrm{C}$ & $\mathrm{O}$ & $\mathrm{N}$ & $\mathrm{Mg}$ & $\mathrm{Mn}$ & $\mathrm{Cr}$ & $\mathrm{Fe}$ & $\mathrm{Ni}$ & $\mathrm{Si}$ & $\mathrm{Cu}$ & $\mathrm{Al}$ \\
\hline 0.019 & 0.45 & 0.004 & 4.5 & 0.70 & 0.16 & 0.20 & 0.019 & 0.13 & 0.014 & balance \\
\hline
\end{tabular}



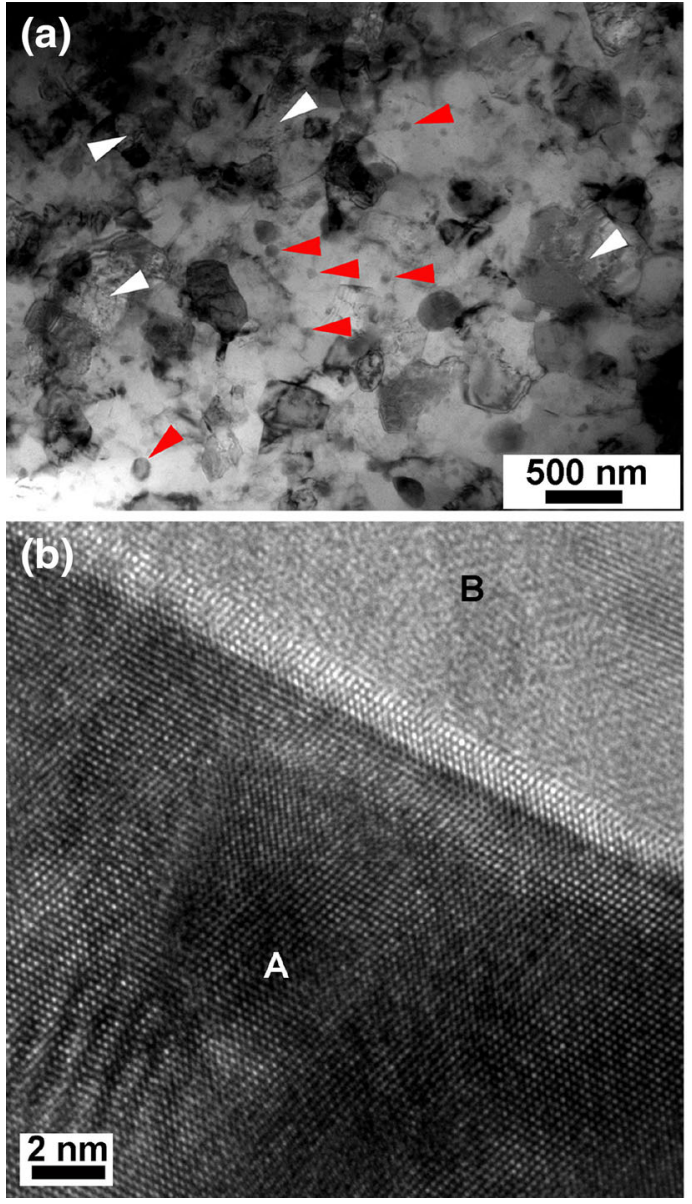

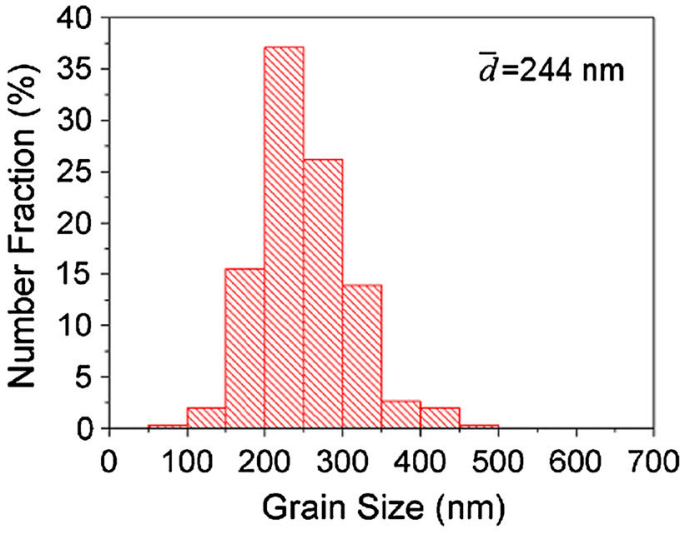

(c)

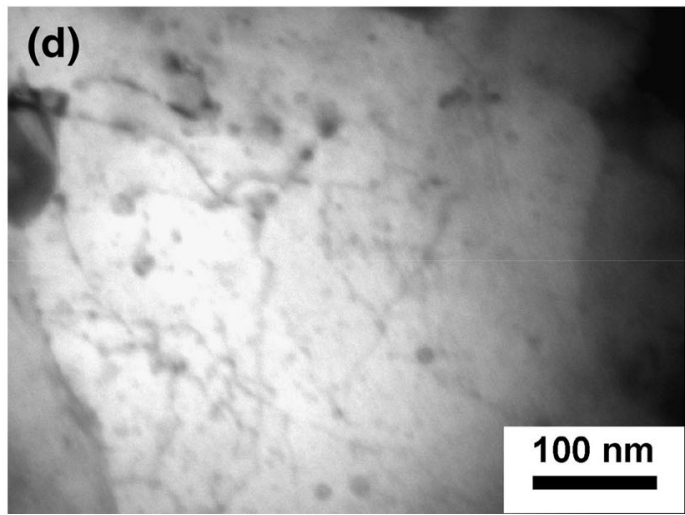

Fig. 1-The microstructure of the as-HIPped $5083 \mathrm{Al}$ : (a) TEM BF micrograph showing grains and second-phase particles (indicated by red and white arrowheads), (b) HRTEM micrograph showing the GB between two neighboring grains, $(c)$ statistical distribution of grain size, and $d$ ) TEM BF micrograph showing the finer second-phase particles at GIs (Color figure online).

Careful inspection of Figure 1(a) shows the presence of dispersed second-phase particles. The second-phase particles can be divided into two categories: i) coarser particles (marked by red arrowheads in Figure 1(a)) of 20 to $100 \mathrm{~nm}$ in size despite the occasional presence of particles $>100 \mathrm{~nm}$, which are distributed at both GBs and GIs; and ii) finer particles (marked by white arrowheads in Figure 1(a)) at GIs, which range from 5 to $20 \mathrm{~nm}$ in size as revealed by a TEM image of higher magnification (Figure 1(d)). The statistical analysis based on a large number of TEM view fields revealed $\sim 30 \mathrm{~nm}$ of the average second-phase particle size $(\bar{l})$ in the as-HIPped $5083 \mathrm{Al}$. Inspection of the published literature ${ }^{[39]}$ indicates that the second phases in the $5083 \mathrm{Al}$ synthesized by consolidation of mechanically milled powders have been identified as $\mathrm{Al}_{12} \mathrm{Mg}_{2}(\mathrm{CrMnFe}), \quad \mathrm{Al}_{12}(\mathrm{FeMn})_{3} \mathrm{Si}$, $\mathrm{Al}_{6}(\mathrm{CrMnFe}), \mathrm{MgO}, \mathrm{SiO}_{2}$, and $\mathrm{CuMgSiAl}$. Given that mechanically milled 5083 Al powders underwent a prolonged period during degassing and HIPping at high temperatures [degassing at $673 \mathrm{~K}\left(400{ }^{\circ} \mathrm{C}\right)$ for 25 hours and HIPping at $648 \mathrm{~K}\left(375^{\circ} \mathrm{C}\right)$ for 4 hours], the as-HIPped $5083 \mathrm{Al}$ can be considered to achieve the equilibrium state and consequently, the volume fractions of the various second-phase particles were determined primarily by the equilibrium thermodynamic conditions [i.e., the equilibrium solubility of elements in the matrix $\mathrm{Al}$ at $\left.648 \mathrm{~K}\left(375^{\circ} \mathrm{C}\right)\right]$. Given the extremely low equilibrium solubility of $\mathrm{Mn}, \mathrm{Cr}, \mathrm{Fe}$, and $\mathrm{O}$ in $\mathrm{Al}^{[40]}$ and relatively high contents of these elements (Mn 0.7 wt pct, $\mathrm{Cr} 0.16 \mathrm{wt}$ pct, Fe $0.20 \mathrm{wt}$ pct, and $\mathrm{O} 0.45 \mathrm{wt}$ pct $)$ and of $\mathrm{Si}(0.13 \mathrm{wt}$ pct $)$, appreciable amounts of $\mathrm{Al}_{12} \mathrm{Mg}_{2}(\mathrm{CrMnFe}), \mathrm{Al}_{12}$ $(\mathrm{FeMn})_{3} \mathrm{Si}, \mathrm{Al}_{6}(\mathrm{CrMnFe})$, and $\mathrm{MgO}$ should be observed. In the present $5083 \mathrm{Al}, \mathrm{Cu}$-containing particles $(\mathrm{CuMg}-$ $\mathrm{SiAl}$ ), as well as carbide, nitride, and Ni-containing particles, were rarely found due to the very low contents of $\mathrm{Cu}$ (0.014 wt pct), C (0.019 wt pct), N (0.004 wt pct), and $\mathrm{Ni}(0.019$ wt pct). Based on the above discussion, the second-phase particles in the as-HIPped $5083 \mathrm{Al}$ should primarily comprise the following phases $\mathrm{Al}_{12} \mathrm{Mg}_{2}$ $(\mathrm{CrMnFe}), \mathrm{Al}_{12}(\mathrm{FeMn})_{3} \mathrm{Si}, \mathrm{Al}_{6}(\mathrm{CrMnFe})$, and $\mathrm{MgO}$.

\section{B. Microstructure of the Annealed $5083 \mathrm{Al}$}

Figure 2(a) shows the typical TEM microstructure of the annealed $5083 \mathrm{Al}$. Based on statistical analysis of 421 grains observed in a series of randomly selected TEM images, the grain size distribution was reported in 
Figure 2(b), and the average grain size was evaluated as $\bar{d}=262 \mathrm{~nm}$. Comparison of the average grain size of the annealed $5083 \mathrm{Al}(262 \mathrm{~nm})$ with that of the as-HIPped $5083 \mathrm{Al}(244 \mathrm{~nm})$ shows that very slight grain growth occurred during annealing.

In addition, by statistical analysis of the secondphases particles in the as-HIPped $5083 \mathrm{Al}$ (e.g., as shown in Figures 1(a) and (d)) and those in the annealed $5083 \mathrm{Al}$ (e.g., as displayed in Figures 2(a) and (c), the latter being the higher-magnification TEM image of finer particles), it is revealed that, although subjected to annealing at $673 \mathrm{~K}\left(400{ }^{\circ} \mathrm{C}\right)$ for 5 hours, the volume fraction, size, and distribution of both coarser and finer particles remain almost unchanged. Based on the discussion in Section III-A, the as-HIPped $5083 \mathrm{Al}$ was in an equilibrium state. Thus, during annealing of the as-HIPped $5083 \mathrm{Al}$, the volume fraction of the second-phase particles was also determined by the equilibrium solubility of the elements. Due to the very low equilibrium solubility of $\mathrm{Mn}, \mathrm{Cr}, \mathrm{Fe}$, and $\mathrm{O}$ in $\mathrm{Al},{ }^{[40]}$ the effect of the difference in equilibrium solubility of these elements at $648 \mathrm{~K}$ and $673 \mathrm{~K}\left(375^{\circ} \mathrm{C}\right.$ and $\left.400{ }^{\circ} \mathrm{C}\right)$ on the amounts of second-phase particles containing these elements, including $\mathrm{Al}_{12} \mathrm{Mg}_{2}(\mathrm{CrMnFe}), \mathrm{Al}_{12}$ $(\mathrm{FeMn})_{3} \mathrm{Si}, \mathrm{Al}_{6}(\mathrm{CrMnFe})$, and $\mathrm{MgO}$, can be neglected. Again, as a result of very low contents of $\mathrm{Cu}, \mathrm{C}, \mathrm{N}$, and $\mathrm{Ni}$, it is highly unlikely that $\mathrm{CuMgSiAl}$, carbide, nitride, and Ni-containing particles are present in the annealed $5083 \mathrm{Al}$. Accordingly, it is appropriate to assume that the volume fraction of the second-phase particles remains essentially unchanged. The unchanged size and distribution of the second-phase particles suggest a high thermal stability of the four types of secondphase particles. This phenomenon can be attributed to the extremely low equilibrium solubility ${ }^{[40]}$ and/or diffusivity ${ }^{[41]}$ of some constituent elements of the four types of particles (i.e., $\mathrm{Mn}, \mathrm{Cr}, \mathrm{Fe}$, and $\mathrm{O}$ ) in the matrix $\mathrm{Al}$, which inhibits the dissolution-precipitation process responsible for coarsening of the second-phase particles. ${ }^{[42,43]}$

\section{Microstructure of the Extruded $5083 \mathrm{Al}$}

The TEM BF image in Figure 3(a) shows the typical microstructure of the extruded $5083 \mathrm{Al}$. In the extruded materials, the grain size distribution was statistically analyzed by measuring grains that exhibit strong diffraction conditions (i.e., a low-index zone axis is parallel or close to the direction of the incoming electron beam) and thus appear dark and have clear boundaries with the neighboring grains in the TEM BF images. Such grains are normally characterized by high misorientations (i.e., HAGBs) with the neighboring grains, ${ }^{[44,45]}$ which can be confirmed via HRTEM analysis (Figure 3(b)). Based on the measurements of 412 grains, the grain size distribution exhibited an average grain size of $\vec{d}=647 \mathrm{~nm}$, as shown in Figure 3(c). By comparing the average grain sizes of the as-HIPped $(244 \mathrm{~nm})$ and the extruded $(647 \mathrm{~nm}) 5083 \mathrm{Al}$, it is evident that significant grain growth, by a factor of $\sim 2.7$, occurred during extrusion.
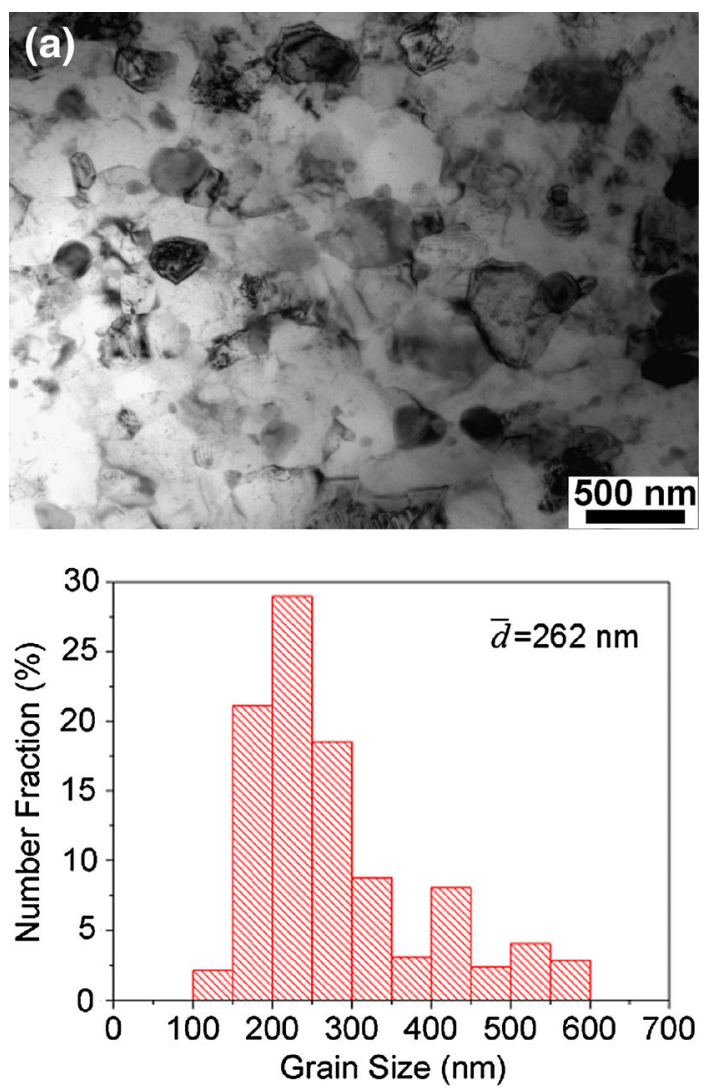

(b)

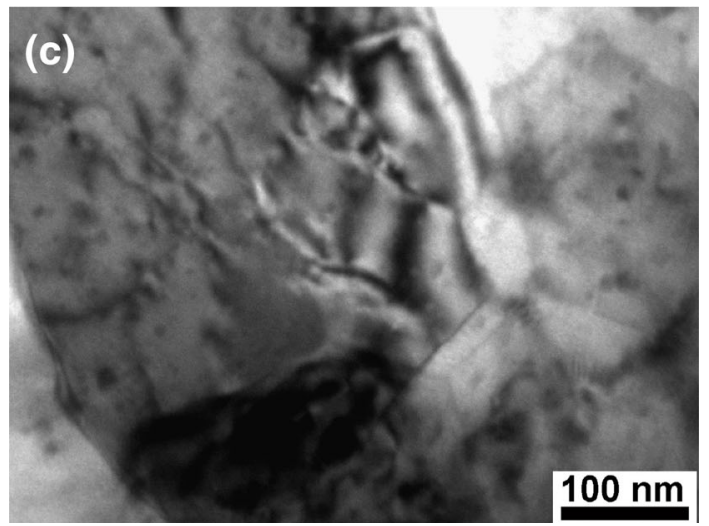

Fig. 2-The microstructure of the annealed $5083 \mathrm{Al}$ : (a) TEM BF micrograph showing grains and second-phase particles, (b) statistical distribution of grain size, and (c) TEM BF micrograph showing the finer second-phase particles at GIs (Color figure online).

In addition, via quantitative analysis of the secondphase particles in the as-HIPped $5083 \mathrm{Al}$ (as shown in Figures 1(a) and (d)) as well as those in the extruded $5083 \mathrm{Al}$ (as displayed in Figures 3(a) and (d), the latter being the higher-magnification TEM image of finer particles in extruded $5083 \mathrm{Al}$ ), the volume fraction, size, and distribution of both coarser and finer particles remain almost unchanged. The unchanged volume fraction of the second-phase particles in the extruded $5083 \mathrm{Al}$ can be rationalized as follows. As analyzed in Section III-A, the as-HIPped $5083 \mathrm{Al}$ was characterized by an equilibrium state. In the present study, extrusion 

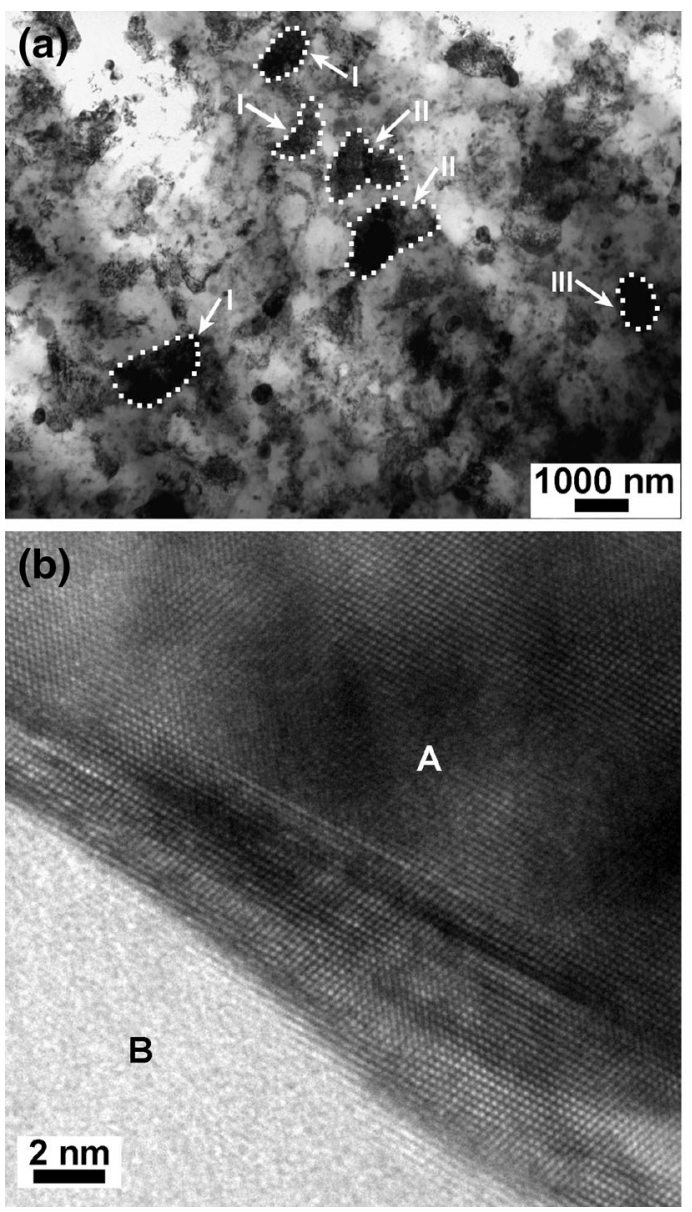

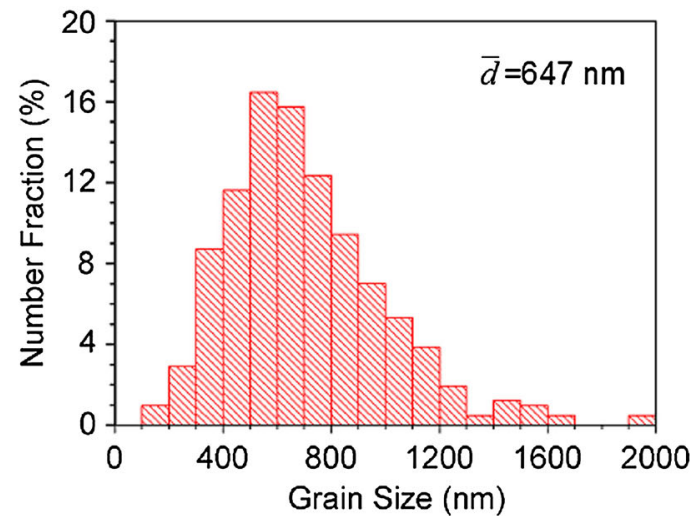

(c)

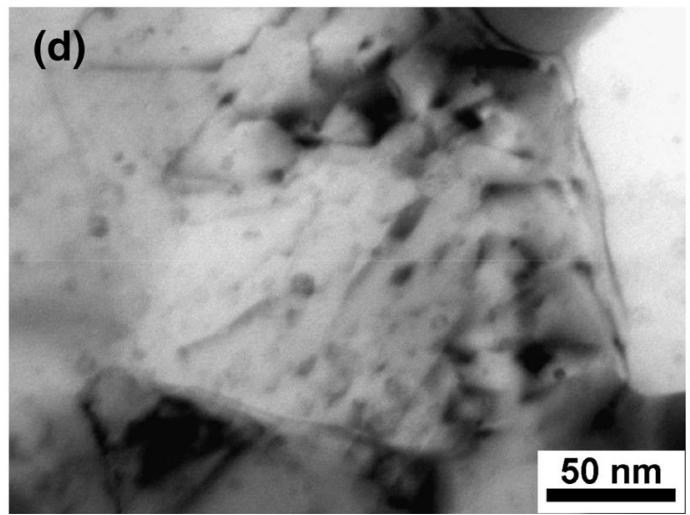

Fig. 3-The microstructure of the extruded $5083 \mathrm{Al}$ : (a) TEM BF micrograph showing grains with three different features (marked by I to III) and second-phase particles, (b) HRTEM micrograph showing the GB between two neighboring grains, $(c)$ statistical distribution of grain size, and (d) TEM BF micrograph showing the finer second-phase particles at GIs (Color figure online).

of $5083 \mathrm{Al}$ was performed at a temperature as high as $673 \mathrm{~K}\left(400{ }^{\circ} \mathrm{C}\right.$ ) (homologous temperature of $\sim 0.80$ ) with a moderate straining magnitude of 2.3 under a relatively low strain rate of $0.8 \mathrm{~s}^{-1}$. Thus, $5083 \mathrm{Al}$ can be presumably considered to undergo an equilibrium process during hot extrusion. The volume fraction of the second-phase particles during hot extrusion of as-HIPped $5083 \mathrm{Al}$ was also primarily determined by the equilibrium solubility of the elements, as discussed above. Given the fact the elements $\mathrm{Mn}, \mathrm{Cr}, \mathrm{Fe}$, and $\mathrm{O}$ in $\mathrm{Al}$ exhibit an extremely low equilibrium solubility in $\mathrm{Al},{ }^{[40]}$ we can presumably neglect any effects associated with differences in equilibrium solubility of these elements at $648 \mathrm{~K}$ and $673 \mathrm{~K}\left(375^{\circ} \mathrm{C}\right.$ and $\left.400{ }^{\circ} \mathrm{C}\right)$ on the volume fractions of the second-phase particles containing these elements, i.e., $\mathrm{Al}_{12} \mathrm{Mg}_{2}(\mathrm{CrMnFe})$, $\mathrm{Al}_{12}(\mathrm{FeMn})_{3} \mathrm{Si}, \mathrm{Al}_{6}(\mathrm{CrMnFe})$, and $\mathrm{MgO}$. As discussed in Section III-B, the very low contents of $\mathrm{Cu}, \mathrm{C}, \mathrm{N}$, and $\mathrm{Ni}$ lead to negligible volume fractions of $\mathrm{CuMgSiAl}$, carbide, nitride, and Ni-containing particles. The unchanged size and distribution of the second-phase particles are attributable to two factors: (1) high thermal stability of the second-phase particles in $5083 \mathrm{Al}$ as discussed in Section III-B, and (2) negligible fragmentation of the nano-scale second-phase particles during plastic deformation, consistent with experimental observations in the published literature. ${ }^{[35,46]}$

Careful inspection of the microstructure at GIs in the extruded 5083 Al (Figure 3(a)) reveals three types of grains based on microstructural features at GIs. First, most grains (as marked by "I" in Figure 3(a) as examples) contain well-defined smaller subgrains with size ranging from $\sim 100$ to $\sim 300 \mathrm{~nm}$. The subgrain structure inside such grains can be more clearly demonstrated in a highmagnification TEM micrograph (Figure 4(a)), where the GBs are delineated by dots and subgrains are marked by "SG." The HRTEM micrograph (the zone axis $\langle 110\rangle$ parallel to the incoming electron beam direction) as shown in Figure 4(b) confirms the presence of the lowangle subgrain boundaries (SGBs) with misorientation of 2 to $3 \mathrm{deg}$ between the subgrains. It is noted that, in addition to the subgrains (marked by " $S G$ " in Figure 4(a)), there exists a region (marked by " $D$ ") where subgrain structure was not well developed and consequently, SGBs cannot be observed. HRTEM observation indicates an almost identical orientation inside the region (not shown herein). Second, TEM examination also reveals some grains (marked by "II" in Figure 3(a) as examples) that consist of only larger well-defined subgrains with size falling in the range of $\sim 450$ to $\sim 1000 \mathrm{~nm}$. 

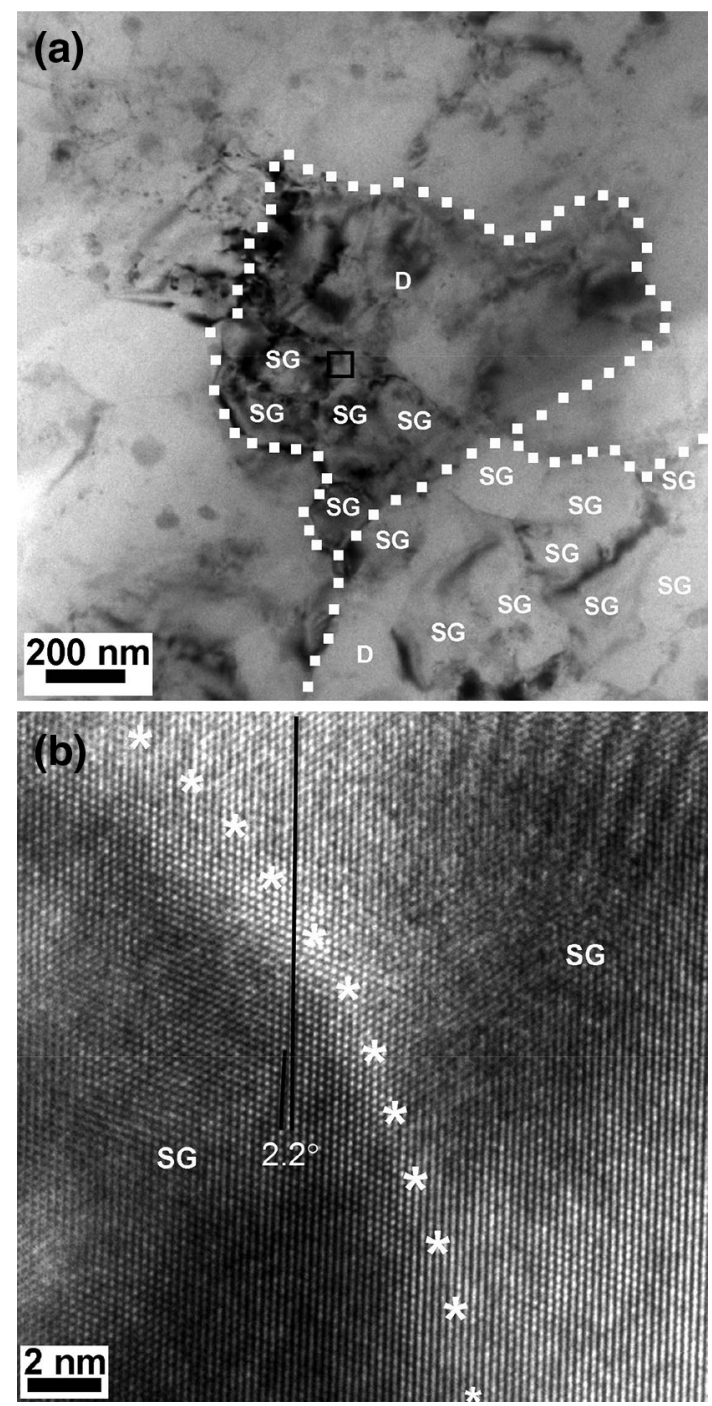

Fig. 4-Higher-magnification micrograph of grains with microstructural features marked by "I" in Fig. 3(a): (a) microstructure at the GIs, where the HAGBs are delineated by dotted lines, the subgrains are marked by "SG," and the regions where SGBs are not developed are marked by "D," and (b) HRTEM micrograph of the region marked by a black square in (a), showing the low-angle SGB, where the SGB is delineated by the asterisks and the low-misorientation angle $(<15 \mathrm{deg})$ is revealed by the two straight black lines.

The high-magnification TEM microstructure of this type of grains is shown in Figure 5(a). Again, the presence of low-angle SGBs inside the grain was confirmed by the HRTEM analysis as shown in Figure 5(b). Third, in addition to the grains containing a subgrain structure (both smaller and larger subgrain sizes as mentioned above), grains, inside which subgrain structure was not well developed, can also be observed, as marked by "III" in Figure 3(a). The high-magnification TEM microstructure of this type of grains is shown in Figure 6.

\section{XRD Results}

The XRD patterns of gas-atomized $5083 \mathrm{Al}$ powders, the as-HIPped, and the extruded bulk $5083 \mathrm{Al}$ are shown in
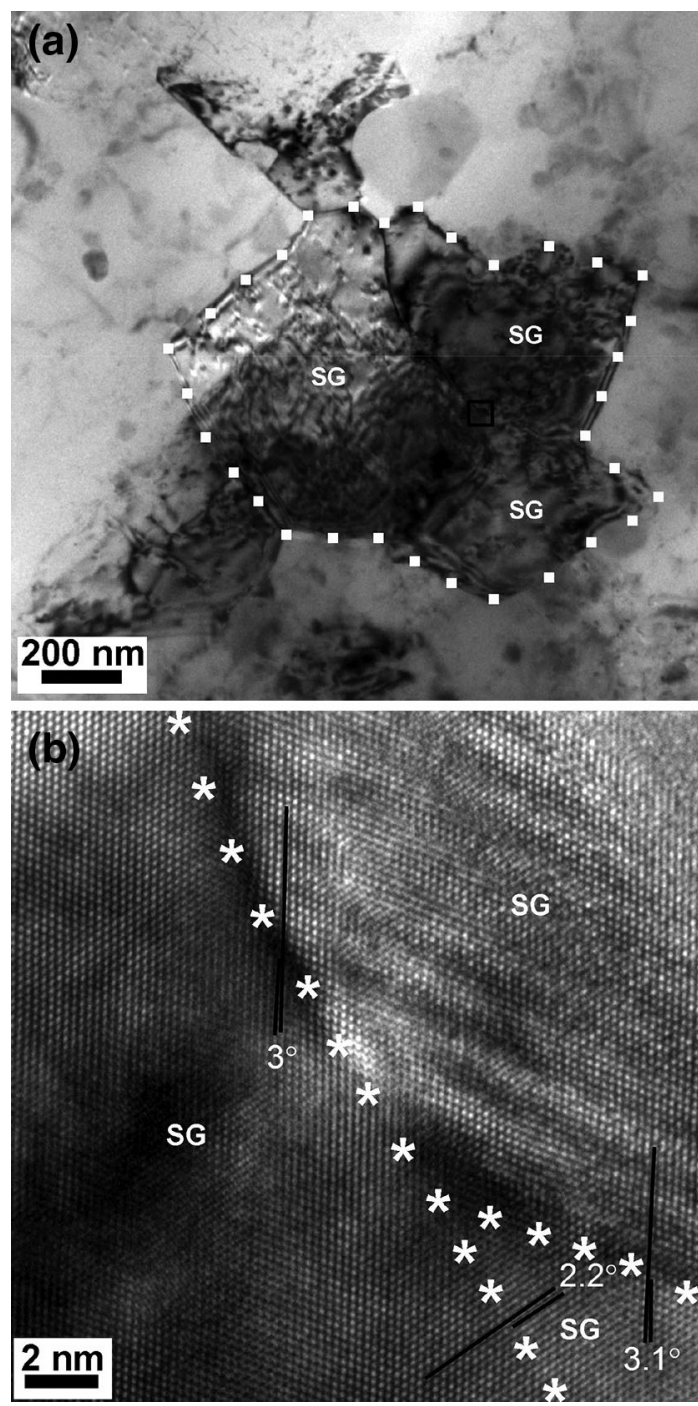

Fig. 5-Higher-magnification micrograph of a grain with microstructural features marked by "II" in Fig. 3(a): (a) microstructure at the GIs, where the HAGBs are delineated by dotted lines and the subgrains are marked by "SG," and (b) HRTEM micrograph of the region marked by a black square in (a), showing the low-angle SGBs, where the SGBs are delineated by the asterisks and each of the low-misorientation angles $(<15 \mathrm{deg})$ between two neighboring subgrains is revealed by the two straight black lines.

Figure 7. Each pattern exhibits five peaks corresponding to $\{111\},\{200\},\{220\},\{311\}$, and $\{222\}$. The intensities of the diffraction peaks were taken from these XRD patterns, as given in Table II. The crystallographic textures in the aforementioned materials were determined based on the intensities using a model originally developed by Lotgering. ${ }^{[47]}$ In the model, the degree of orientation of a crystal plane $\{h k l\}, O_{h k l}$, is defined as:

$$
O_{h k l}=\frac{V_{h k l}-V_{h k l, 0}}{1-V_{h k l, 0}}
$$

where $V_{h k l}=I_{h k l} / \sum I_{h k l}\left(I_{h k l}\right.$ is the intensity of the peak corresponding to $\{h k l\}$ and $\sum I_{h k l}$ is the sum of intensity of all peaks for the investigated bulk material) and $V_{h k l, 0}=I_{h k l, 0} / \sum I_{h k l, 0}\left(I_{h k l, 0}\right.$ is the intensity of the peak 
corresponding to $\{h k l\}$ and $\sum I_{h k l, 0}$ is the sum of intensity of all peaks for the corresponding powder diffraction). Based on the intensities provided in Table II, the degrees of orientation of various $\{h k l\}$ were then calculated, as reported in Table III. It is noted that, when the calculations were performed, only the intensities corresponding to the five peaks in Figure 7 were used to obtain the sums of intensities. Since the sum of intensities corresponding to the five peaks accounts for a predominant percentage of the total sum of intensities of all peaks, ${ }^{[4]}$ those corresponding to other peaks can be safely neglected. The

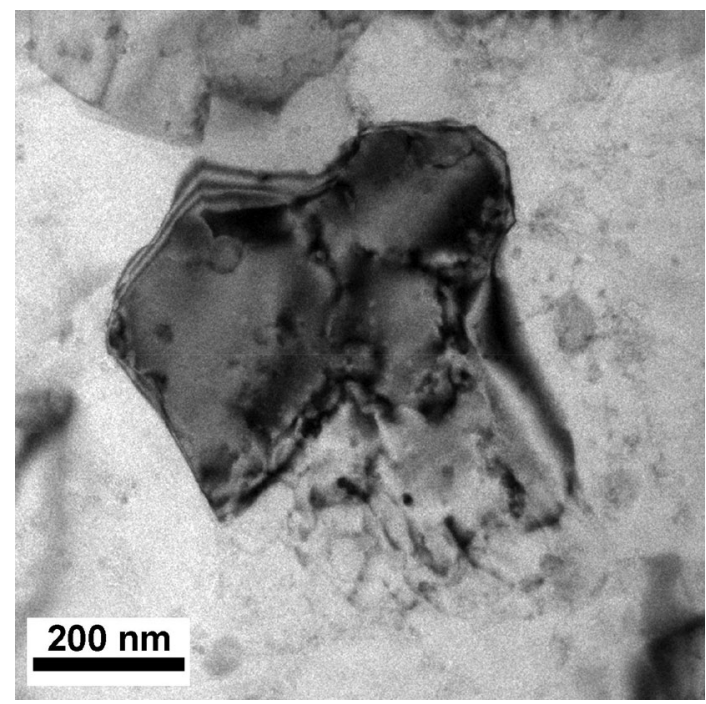

Fig. 6-Higher-magnification TEM micrograph of an on-axis dark grain, showing the microstructural features marked by "III" in Fig. 3a.

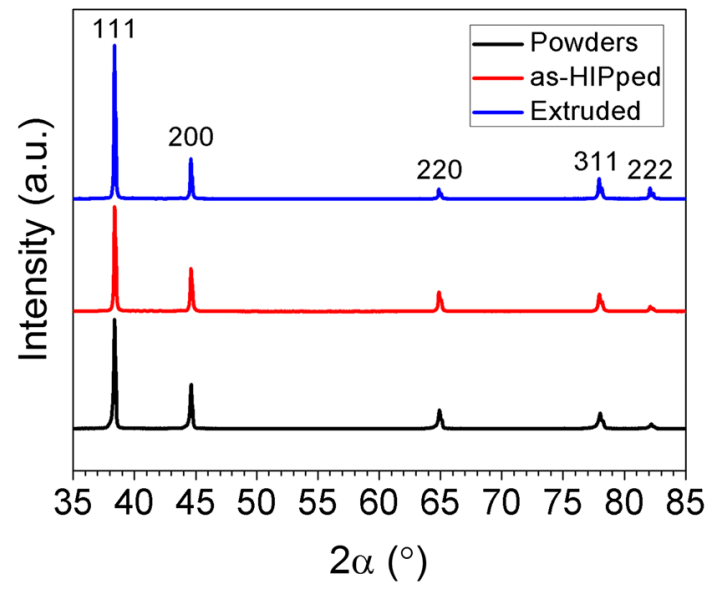

Fig. 7-XRD patterns of gas-atomized $5083 \mathrm{Al}$ powders, as-HIPped, and extruded $5083 \mathrm{Al}$ (Color figure online). model proposed that $O_{h k l}=0$ and 1 correspond to completely random (e.g., powders) and preferential (e.g., a single crystal) orientations, respectively, and accordingly, $0<O_{h k l}<1$ represents the presence of $\{h k l\}$ texture to a certain extent. Based on the aforementioned discussion, the calculated degrees of orientation in Table III suggest that the as-HIPped 5083 Al are randomly oriented and no textures are present, and that only $\{111\}$ texture was developed in the extruded $5083 \mathrm{Al}$, which is consistent with the previously reported texture in the UFG A1-7.5 wt pet Mg synthesized by HIPping of mechanically milled powders followed by hot extrusion. ${ }^{[49]}$ In Reference 49, it is observed that two spots in the $\{111\}$ ring of the selected area electron diffraction pattern, which represent the crystallographic direction parallel to the extrusion direction, exhibit much higher intensity than that of other locations in the ring, suggesting a $\langle 111\rangle$ fiber texture parallel to the extrusion direction; in contrast, other rings in the diffraction pattern show fairly uniform intensity, indicating that other types of texture were not developed.

Based on XRD peak broadening after subtraction of instrumental broadening, the average dimension of coherent domains $\left(\bar{d}_{\mathrm{CD}}\right)$ and microstrain $\left(\left\langle\varepsilon^{2}\right\rangle^{1 / 2}\right)$ can be determined using the following equation ${ }^{[50]}$ :

$$
\frac{\Delta_{\alpha}^{2}}{\tan ^{2} \alpha}=\frac{\lambda}{\bar{d}_{\mathrm{CD}}} \frac{\Delta_{\alpha}}{\tan \alpha \sin \alpha}+25\left\langle\varepsilon^{2}\right\rangle
$$

where $\lambda$ is the $\mathrm{X}$-ray wave-length, $\alpha$ is the angle corresponding to the peak maximum position, and $\Delta_{\alpha}$ is the integral breadth corresponding to $\alpha$ after subtraction of instrumental broadening effect. By performing a least-square fit to $\frac{\Delta_{\alpha}^{2}}{\tan ^{2} \alpha}$ against $\frac{\Delta_{\alpha}}{\tan \alpha \sin \alpha}$ for all measured peaks, $\bar{d}_{\mathrm{CD}}$ and $\left\langle\varepsilon^{2}\right\rangle^{1 / 2}$ can be obtained. $\left\langle\varepsilon^{2}\right\rangle^{1 / 2}$ can be used to evaluate the dislocation density $\rho$ by the following equation ${ }^{[51,52]}$.

$$
\rho=\frac{2 \sqrt{3}\left\langle\varepsilon^{2}\right\rangle^{1 / 2}}{b \bar{d}_{\mathrm{CD}}}
$$

where $b$ is Burgers vector. Using Eq. [3], the calculated dislocation densities are $\sim 2.4 \times 10^{14}$ and $\sim 7.7 \times$ $10^{13} \mathrm{~m}^{-2}$, corresponding to the as-HIPped and the extruded $5083 \mathrm{Al}$, respectively.

Table III. The Calculated Degrees of Orientation in the asHIPped and Extruded 5083 Al

\begin{tabular}{lcccc}
\hline & $\{111\}+\{222\}$ & $\{200\}$ & $\{220\}$ & $\{311\}$ \\
\hline As-HIPped & $\sim 0$ & $\sim 0$ & $\sim 0$ & $\sim 0$ \\
Extruded & $\sim 0.27$ & $\sim 0$ & $\sim 0$ & $\sim 0$ \\
\hline
\end{tabular}

\begin{tabular}{|c|c|c|c|c|c|}
\hline & $\{111\}$ & $\{200\}$ & $\{220\}$ & $\{311\}$ & $\{222\}$ \\
\hline Powders & 6529 & 2652 & 1142 & 956 & 287 \\
\hline As-HIPped & 6221 & 2539 & 1136 & 1012 & 294 \\
\hline Extruded & 9148 & 2382 & 594 & 1215 & 656 \\
\hline
\end{tabular}

Table II. The Intensities of Peaks in the XRD Patterns of Gas-Atomized 5083 Al Powders, as-HIPped, and Extruded 5083 Al 


\section{E. APT Results}

Figure 8(a) shows a typical 3D APT reconstruction for the $5083 \mathrm{Al}$ extruded at $673 \mathrm{~K}\left(400{ }^{\circ} \mathrm{C}\right)$ with atoms of all elements present in the material displayed. Careful inspection reveals the presence of a GB in the reconstructed volume, which is clearly delineated by the 6 at. pct $\mathrm{Mg}$ isoconcentration surface (Figure 8(b)) due to strong $\mathrm{Mg}$ segregation at the GB. A selection box with the Z-axis parallel to the GB plane normal was implemented to measure the concentrations of $\mathrm{Al}$ and various solutes across the GB, and the concentration profiles are shown in Figures 8(c) and (d). In addition, the solute concentrations at GBs and at GIs were measured using rectangular or cylindrical selection boxes, whose sizes were selected such that only the matrix solid solutions were included within the analysis boxes. The measurements of solute concentrations were performed for multiple analysis volumes corresponding to multiple APT datasets. The measurements revealed the GB segregation layers of 5 to $10 \mathrm{~nm}$ in thickness. The averaged concentration values from the multiple APT datasets for GIs and GBs are reported in Table IV. It is clearly shown that, for all solutes, the concentrations at GBs are higher than those at GIs, indicative of

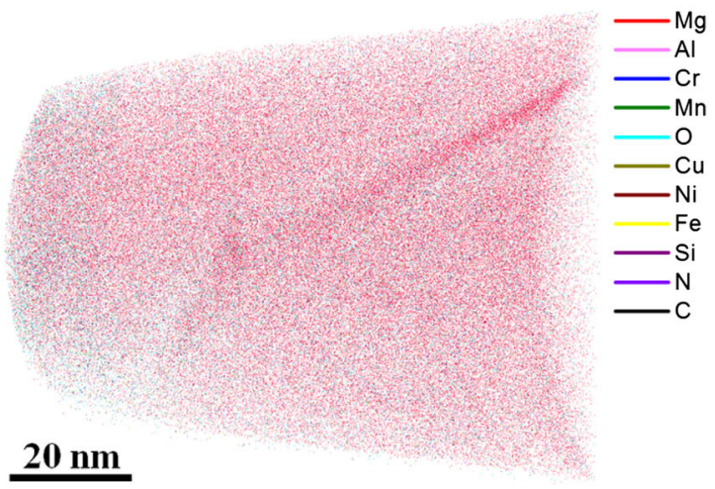

(a)

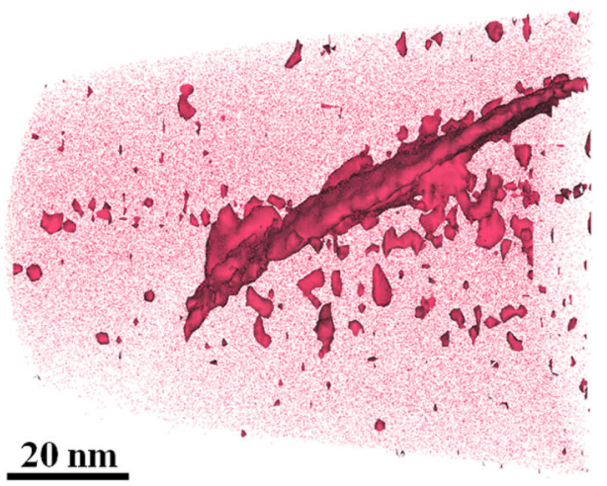

(b) solute segregation at GBs. However, it is noted that, despite solute segregation at GBs, the absolute values of solute concentrations at GBs are still very low except for that of $\mathrm{Mg}$ as a result of very low overall contents of these elements (Table I). Accordingly, GB segregation of these elements is not evident from the atom maps, and the GBs cannot be delineated by isoconcentration surfaces of elements other than $\mathrm{Mg}$. As discussed in Section III-C, 5083 Al may undergo an equilibrium process during hot extrusion. Hence, GB segregation occurring during hot extrusion can be considered to be of an equilibrium nature, which is primarily related to temperature. ${ }^{[53]}$ Based on this discussion, it is considered appropriate to assume that the annealed and the extruded $5083 \mathrm{Al}$ exhibit the same general solute segregation at GBs.

Inspection of the published literature reveals that the solutes segregated at GBs generally reduce the GB energy. ${ }^{[54,55]}$ Based on the changes of enthalpy and configurational entropy during grain coarsening, Kirchheim $^{[5]}$ developed a formula that describes the GB energy per unit area $(\gamma)$ as a function of GB segregation of the solute in an ideal dilute binary solution. Given the negligible interactions between different solute elements in an ideal dilute solution containing multiple

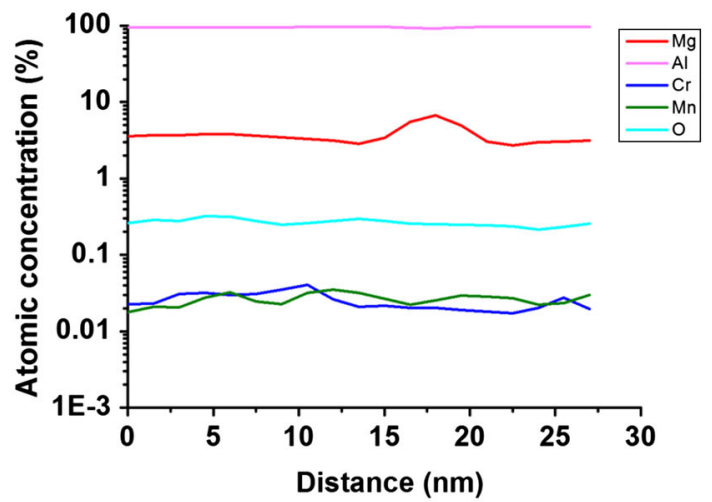

(c)

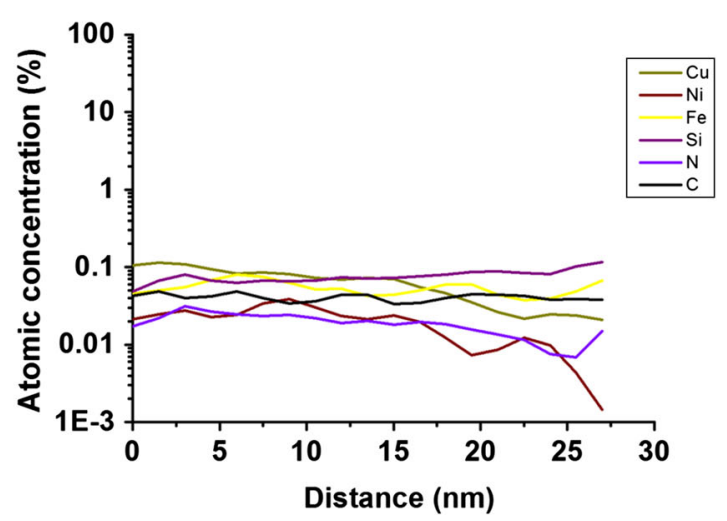

(d)

Fig. 8-The results of APT analysis of the extruded $5083 \mathrm{Al}$ : (a) a typical tomographic 3D reconstruction (9 M atoms in reconstruction) with atoms of all elements displayed in different colors, where a GB is included, $(b) \mathrm{Mg}$ atoms in the reconstruction with 6 at. pct $\mathrm{Mg}$ isoconcentration surface superimposed, which delineates the $\mathrm{GB},(c, d) \mathrm{Al}$ and solutes' concentration profiles across the GB in (a), measured using a selection box with the $Z$-axis parallel to the GB plane normal (Color figure online). 
Table IV. The Concentrations of Al and Solutes at GBs and GIs Measured by APT and the Calculated Solute Excess at GBs

\begin{tabular}{lccc}
\hline Element & Concentration at GBs (At. Pct) & Concentration at GIs (At. Pct) & Solute Excess (mol $/ \mathrm{m}^{2}$ ) \\
\hline $\mathrm{Al}$ & $94.1142 \pm 0.2657$ & $96.4831 \pm 0.1083$ & - \\
$\mathrm{Mg}$ & $5.3283 \pm 0.0347$ & $3.1550 \pm 0.0140$ & $4.43 \times 10^{-6}$ \\
$\mathrm{Mn}$ & $0.1150 \pm 0.0077$ & $0.0408 \pm 0.0018$ & $1.48 \times 10^{-7}$ \\
$\mathrm{Cr}$ & $0.0293 \pm 0.0034$ & $0.0177 \pm 0.0010$ & $2.37 \times 10^{-8}$ \\
$\mathrm{Fe}$ & $0.1054 \pm 0.0062$ & $0.0699 \pm 0.0019$ & $7.33 \times 10^{-8}$ \\
$\mathrm{Ni}$ & $0.0266 \pm 0.0032$ & $0.0138 \pm 0.0009$ & $2.59 \times 10^{-8}$ \\
$\mathrm{Si}$ & $0.0702 \pm 0.0051$ & $0.0651 \pm 0.0020$ & $1.32 \times 10^{-8}$ \\
$\mathrm{Cu}$ & $0.0440 \pm 0.0040$ & $0.0265 \pm 0.0013$ & $3.58 \times 10^{-8}$ \\
$\mathrm{C}$ & $0.0334 \pm 0.0036$ & $0.0273 \pm 0.0014$ & $1.33 \times 10^{-8}$ \\
$\mathrm{O}$ & $0.1110 \pm 0.0088$ & $0.0843 \pm 0.0038$ & $5.67 \times 10^{-8}$ \\
$\mathrm{~N}$ & $0.0226 \pm 0.0030$ & $0.0165 \pm 0.0010$ & $1.28 \times 10^{-8}$ \\
\hline
\end{tabular}

Table V. The Calculated Enthalpy of Segregation at GBs $\left(H_{\mathrm{seg}, i}\right)$ for the Constituent and Impurity Elements in 5083 Al Used in the Present Study $\left(\mathrm{kJ} \mathrm{mol}^{-1}\right)$

\begin{tabular}{cccccccccc}
\hline $\mathrm{Mg}$ & $\mathrm{Mn}$ & $\mathrm{Cr}$ & $\mathrm{Fe}$ & $\mathrm{Si}$ & $\mathrm{Cu}$ & $\mathrm{Ni}$ & $\mathrm{C}$ & $\mathrm{O}$ & $\mathrm{N}$ \\
\hline 34.7 & 52.0 & 25.1 & 37.6 & 36.6 & 20.2 & 89.6 & 27.0 & 71.3 & 70.3 \\
\hline
\end{tabular}

components, using the same arguments as those that Kirchheim used for solute atoms of each element, an equation that correlates $\gamma$ with GB segregation of multiple elements can be derived as follows:

$$
\gamma=\gamma_{0}-\sum_{i}^{m} \Gamma_{i}\left(R T \ln c_{i}^{\mathrm{GI}}+H_{\mathrm{seg}, i}\right)
$$

where $\gamma_{0}$ is the GB energy of pure solvent per unit area, $m$ is the number of the solute type, $\Gamma_{i}$ is the excess of solute $i$ at $\mathrm{GBs}, c_{i}^{\mathrm{GI}}$ is the concentration of solute $i$ at GIs, $H_{\mathrm{seg}, i}$ is the enthalpy of segregation of solute $i, R$ is universal gas constant, and $T$ is the temperature. By selecting a symmetrical tilt $\Sigma 5$ (012) [100] GB to represent the general HAGBs in the present study, $H_{\text {seg }, i}$ is determined via calculations based on first-principles simulations, as shown in Table V; the details can be found in Appendix. Based on the measured solute concentrations at GBs and at GIs, $\Gamma_{i}$ can be assessed by the following equation ${ }^{[56]}$.

$$
\Gamma_{i}=\frac{N^{\mathrm{GB}}}{N_{\mathrm{A}}}\left(c_{i}^{\mathrm{GB}}-c_{\mathrm{sv}}^{\mathrm{GB}} \frac{c_{i}^{\mathrm{GI}}}{c_{\mathrm{sv}}^{\mathrm{GI}}}\right) \chi
$$

where $N^{\mathrm{GB}}$ is the total atomic number per unit volume at GBs, $N_{\mathrm{A}}$ is the Avogadro's constant, $c_{i}^{\mathrm{GB}}$ is the concentration of solute $i$ at $\mathrm{GBs}, c_{\mathrm{sv}}^{\mathrm{GB}}$ and $c_{\mathrm{sv}}^{\mathrm{GI}}$ are the solvent concentrations at GBs and GIs, respectively, and $\chi$ is the GB width (taking $\chi=2 \mathrm{~nm}$ herein ${ }^{[57,58]}$ ). The calculated values of the solute excess are shown in Table IV.

Using the modified Read-Shockley expression, which is valid for both low- and high-angle $\mathrm{GBs},{ }^{[59]} \gamma_{0}$ can be calculated by the equation:

$$
\gamma_{0}=\sin \theta\left[E_{\mathrm{c}}-E_{\mathrm{s}} \ln (\sin \theta)\right] / b,
$$

where $\theta$ is the $\mathrm{GB}$ misorientation ( $\theta$ is taken as $36.9^{\circ}$ for the symmetrical tilt $\Sigma 5(012)[100] \mathrm{GB}^{[64]}$ herein), and $E_{\mathrm{c}}$ and $E_{\mathrm{s}}$ are dislocation-core and strain-field energies. As a result of the unavailability of the data corresponding to $E_{\mathrm{c}} / b$ and $E_{\mathrm{s}} / b$ for pure Al to calculate $\gamma_{0}$ using Eq. [6], we rely on those for metal $\mathrm{Pd}$ that can be found in the published studies ${ }^{[60]}: E_{\mathrm{c}} / b=1.01 \mathrm{Jm}^{-2}$ and $E_{\mathrm{s}} / b=0.70$ $\mathrm{Jm}^{-2}$ at $0 \mathrm{~K}$. With $E_{\mathrm{c}} / b$ and $E_{\mathrm{s}} / b$ being proportional to $G b$ (where $G$ is the shear modulus), ${ }^{[61]}$ the values of $E_{\mathrm{c}} / b$ and $E_{\mathrm{s}} / b$ for pure Al at $673 \mathrm{~K}\left(400{ }^{\circ} \mathrm{C}\right)$ can be calculated as $E_{\mathrm{c}} / b=0.28 \mathrm{Jm}^{-2}$ and $E_{\mathrm{s}} / b=0.20 \mathrm{Jm}^{-2}$, on the basis of the following data $^{[62]}: G=72.5 \mathrm{GPa}$ and $b=0.275 \mathrm{~nm}$ for $\mathrm{Pd}$ at $0 \mathrm{~K}$, and $G=19.5 \mathrm{GPa}$ $\left(G=30.22-0.016 T(\mathrm{GPa})^{[63]}\right)$ and $b=0.286 \mathrm{~nm}$ for pure $\mathrm{Al}$ at $673 \mathrm{~K}\left(400{ }^{\circ} \mathrm{C}\right)$. The $\mathrm{GB}$ energy per unit area for pure $\mathrm{Al}$ is then calculated to be $\gamma_{0}=0.229 \mathrm{Jm}^{-2}$.

Given the relatively low solute concentrations of constituent and impurity elements in the $5083 \mathrm{Al}$ studied (as shown in Table I), it may be reasonable to assume the solution of the constituent and impurity elements in the matrix Al to be an ideal dilute solution. Based on the assumption, $\gamma$ in the $5083 \mathrm{Al}$ can be evaluated using Eq. [4]. The calculated result indicates that GB segregation reduces the GB energy per unit area at $400{ }^{\circ} \mathrm{C}$ from $\gamma_{0}=0.229 \mathrm{Jm}^{-2}$ for pure Al to $\gamma=0.144 \mathrm{Jm}^{-2}$ for $5083 \mathrm{Al}$ in the present study.

Based on the measured solute concentrations of $\mathrm{Mn}$, $\mathrm{Cr}, \mathrm{Fe}, \mathrm{Si}$, and $\mathrm{O}$ at $\mathrm{GBs}$ (the average thickness of the segregation layers is taken as $7.5 \mathrm{~nm}$ as estimated by averaging 5 to $10 \mathrm{~nm}$ of the segregation layer thickness) and at GIs (average grain size $\bar{d}=647 \mathrm{~nm}$ ), as well as the overall contents of these elements in the $5083 \mathrm{Al}$ (Table I), the amount of these elements in precipitates can be evaluated, and accordingly the volume fractions of $\mathrm{Al}_{12} \mathrm{Mg}_{2}(\mathrm{CrMnFe}), \mathrm{Al}_{12}(\mathrm{FeMn})_{3} \mathrm{Si}, \mathrm{Al}_{6}(\mathrm{CrMnFe})$, and $\mathrm{MgO}$ can be estimated as $1.45,0.84,0.65$, and 0.74 pct, respectively. Thus, the total volume fraction of the second-phase particles is $f=3.68$ pct in the resultant extruded 5083 Al. Based on the discussion in Sections III-B and III-C, the total volume fraction of second-phase particles remained essentially unchanged during the annealing and extrusion processes. 


\section{DISCUSSION}

\section{A. Stress-Induced Grain Growth During Hot Extrusion}

As presented in Section III-B, very limited grain growth occurred during annealing of the as-HIPped $5083 \mathrm{Al}$ at $673 \mathrm{~K}\left(400{ }^{\circ} \mathrm{C}\right)$ for 5 hours. This observation suggests that, in the absence of an applied stress, the two possible mechanisms responsible for grain growth, i.e., GB migration and grain rotation, as discussed in Section I, were almost inhibited by second-phase particles and GB segregation, which is described in detail as follows. First, solute segregation at GBs reduced the GB energy per unit area and thus the driving force for grain growth provided by GB curvature. Second, the thermal stability of second-phase particles, in combination with solute segregation at GBs, promoted the retention of high resistance forces to $\mathrm{GB}$ migration and grain rotation. Both of these factors facilitated the inhibition of grain growth. In contrast, significant grain growth was observed during extrusion of the as-HIPped $5083 \mathrm{Al}$ at $673 \mathrm{~K}\left(400{ }^{\circ} \mathrm{C}\right)$ (the extrusion process lasted for only $\sim 36$ seconds as mentioned in Section II) plus preceding holding at $673 \mathrm{~K}\left(400{ }^{\circ} \mathrm{C}\right)$ for 1 hour. Comparing the processing conditions of annealing and extrusion (i.e., much longer time of exposure to $673 \mathrm{~K}\left(400{ }^{\circ} \mathrm{C}\right)$ for the former than that for the latter, which facilitates thermally activated grain growth for the former) and the grain sizes after annealing and extrusion, it then follows that grain growth during hot extrusion is predominantly influenced by the type and magnitude of externally applied stresses. Although the thermal stability of second-phase particles in combination with solute segregation at GBs tended to maintain high dragging stresses and solute segregation at GBs lowered the driving force for grain growth, our results suggest that the externally applied stresses overcame the resistance forces generated by second-phase particles and GB segregation, enabling GB migration and grain rotation. The mechanisms underlying stress-induced grain growth during extrusion are discussed in the section that follows.

\section{B. Mechanisms Underlying Stress-Induced Grain Growth During Hot Extrusion}

As discussed in Section I, two mechanisms, i.e., GB migration and grain rotation (the latter being caused by $\mathrm{GB}$ translation or sliding for the curved $\mathrm{GBs}{ }^{[22,31]}$ ), are responsible for grain growth. It has been well documented $^{[1,2,64,65]}$ that GB migration is a ubiquitous mechanism underlying grain growth. Recently, the contribution of grain rotation and subsequent grain coalescence to grain growth has been extensively reported for NS materials. ${ }^{[3-5,66]}$ Whether grain rotation was operative or not in the UFG $5083 \mathrm{Al}$ in the present study will be analyzed and discussed as follows. In addition, grain growth involves HAGB motion and consequently, the following three processes may affect grain growth: (1) discontinuous dynamic recrystallization $(\mathrm{dDRX}),{ }^{[64]}$ operated by nucleation of new recrystallized grains and migration of new HAGBs of these grains, consuming the surrounding deformed microstructures, (2) geometric dynamic recrystallization $($ gDRX $),{ }^{[67-69]}$ characterized by relatively localized movement of the existent GBs that have become corrugated, giving rise to impingement of these GBs and production of new equiaxed grains, and (3) transformation from low-angle SGBs to HAGBs. Inspection of published scientific literature ${ }^{[64,70]}$ reveals that the mechanism of transformation from low-angle SGBs to HAGBs generally plays a very limited role during microstructural evolution in most Al alloys subjected to plastic deformation, especially during high-temperature deformation, where the rate of dislocation accumulation is minimized due to the enhanced rate of dislocation annihilation by the elevated temperatures. Actually, during hot extrusion in the present study, the dislocation density decreased from $2.4 \times 10^{14} \mathrm{~m}^{-2}$ in the beginning (in the as-HIPped $5083 \mathrm{Al}$ ) to $7.7 \times 10^{13} \mathrm{~m}^{-2}$ at the end of extrusion. The likelihood for dDRX and gDRX to operate in the present study will be also analyzed and discussed as follows.

The possibility that dDRX occurred during hot extrusion is first examined based on the analysis of crystallographic texture. The results of crystallographic texture analysis presented in Section III-D indicate that the strong $\langle 111\rangle$ fiber texture was developed while the $\langle 100\rangle$ fiber texture was undetectable following hot extrusion of the almost randomly oriented as-HIPped $5083 \mathrm{Al}$. Inspection of the published literature indicates that, for $\mathrm{Al}$ alloys (e.g., Al-Mg alloys) of high stacking fault energy (SFE) subjected to uniaxial deformation, such as extrusion, the $\langle 111\rangle$ fiber texture component is predominant in the deformed state, ${ }^{[71,72]}$ and an appreciable concentration of the $\langle 100\rangle$ fiber texture component can always be observed in the Al-Mg alloys that undergo dDRX. ${ }^{[72-75]}$ Based on the preceding discussion, it is suggested that, in the present study, the presence of the $\langle 111\rangle$ fiber texture component represents the occurrence of dislocation slip that provides a mechanism to accommodate the plastic strain during extrusion, and the absence of the $\langle 100\rangle$ fiber texture component indicates inhibition of $\mathrm{dDRX}$ during hot extrusion. Inspection of the published literature reveals that, in NS and UFG materials, when the HAGB area fraction exceeds 70 pct, the HAGBs form a stable network that can prevent the occurrence of $\mathrm{dDRX} \cdot{ }^{[76]} \mathrm{In}$ related work, Humphreys suggested that, in Al alloys, more than 64 pct of the HAGB area fraction can completely inhibit dDRX by stabilizing the deformed microstructure against heterogeneous microstructural evolution (e.g., $\mathrm{dDRX}^{[67,69]}$ ). Suppression of $\mathrm{dDRX}$ in the present study can be presumably attributed to more than 70 pct of the HAGB area fraction throughout hot extrusion.

The possibility that gDRX occurred during hot extrusion is then analyzed as follows. References 68 and 77 describe the fundamental mechanisms that underlie gDRX of an Al alloy. During high-temperature deformation, the HAGB spacing decreases along a certain direction; simultaneously, inside the grains subgrains with low-angle boundaries (misorientation $<15 \mathrm{deg}$ ) are progressively developed via DRV due to a 
high SFE of the Al alloy that facilitates motion and rearrangement of dislocations by minimizing dissociation of unit dislocations ${ }^{[64]}$ until a steady state is reached. In the present study (5083 Al deformed at temperature of $673 \mathrm{~K}\left(400^{\circ} \mathrm{C}\right)$ with strain rate of $0.8 \mathrm{~s}^{-1}$ as presented in Section II), the strain value corresponding to onset of the steady state is estimated as 0.3 to $0.5 .^{[78,79]}$ Under steady-state conditions, the subgrain size remains almost unchanged with increasing the magnitude of the strain. When the spacing decreases, the HAGBs always become corrugated due to the surface tension of low-angle SGBs. Pinned by SGBs, the adjacent corrugated HAGBs cannot impinge each other when the HAGB spacing is larger than subgrain size. When the HAGB spacing decreases to a value that is close to the subgrain size, the HAGBs pinch off due to minimized pinning of SGBs and gDRX then occurs, leading to the fragmentation of the original grains and the generation of new equiaxed grains. Based on the preceding discussion, in an effort to determine the possibility for gDRX to occur, the steady-state subgrain size produced by DRV $(\delta)$ during hot extrusion in the UFG $5083 \mathrm{Al}$ is required. There are no data available for the subgrain sizes in $5083 \mathrm{Al}$ containing nanoscale second-phase particles (e.g., the average size $\sim 30 \mathrm{~nm}$ ) that underwent high-temperature deformation. In order to render the problem tractable, we will estimate the subgrain size herein. Inspection of the available scientific literature reveals that, during high-temperature deformation of an $\mathrm{Al}$ alloy, the $\delta$ value is a sole function of Zener-Hollomon parameter $(Z)$ by the following empirical correlation ${ }^{[79,80]}$ :

$$
\delta^{-1}=A+B \ln Z
$$

where $A$ and $B$ are the material constants, and $Z$ is the combination of strain rate $(\dot{\varepsilon})$ and the deformation temperature $(T)$ as defined by ${ }^{[81]}$ :

$$
Z=\dot{\varepsilon} \exp (Q / R T)
$$

where $Q$ is the apparent activation energy of hightemperature deformation. The values of $Q, A$, and $B$ of the UFG $5083 \mathrm{Al}$ in the present study will be determined via extrapolation based on the published data, which is presented as follows.

Relative to pure $\mathrm{Al}$, the $Q$ value of an $\mathrm{Al}$ alloy is usually higher as a result of the retardation of DRV by solutes and second-phase particles. ${ }^{[79,82]}$ For $5083 \mathrm{Al}$ where most $\mathrm{Mg}$ is dissolved in the $\mathrm{Al}$ matrix and other alloying elements than $\mathrm{Mg}$, including $\mathrm{Mn}, \mathrm{Cr}, \mathrm{Fe}$, etc., are precipitated in the form of second-phase particles, ${ }^{[25,38]}$ an increase in $Q$ is primarily attributable to the combined contributions of both the $\mathrm{Mg}$ solute and the second-phase particles, which are determined as follows. For a single-phase Al-Mg binary alloy, the increase in $Q$ represents the influence of the solute $\mathrm{Mg}$ concentration. Based on available data in published studies, ${ }^{[83-88]}$ the increase in $Q$ of a series of single-phase Al-Mg alloys, where $\mathrm{Mg}$ is the predominant solute, relative to that of pure $\mathrm{Al}$ as a function of $\mathrm{Mg}$ concentration is plotted in Figure 9(a), with a linear fitting coefficient in excess of 0.99. For an $\mathrm{Al}-\mathrm{Mg}$ alloy that contains $\mathrm{Mg}$ as the predominant solute and the second-phase particles, the contribution of the second-phase particles to the increase in $Q$ can be obtained by subtraction of the contribution of the solute $\mathrm{Mg}$ from the total increased amount. Moreover, inspection of the published literature ${ }^{[64]}$ reveals that the influence of the second-phase particles on DRV and thereby $Q$ can be reflected by a parameter, namely "particle dispersion level" defined as $f / \bar{l}$. Based on available data in the published studies. ${ }^{[68,79,86,89,90]}$ the increase in $Q$ of $\mathrm{Al}$ alloys, where $\mathrm{Mg}$ is the predominant solute, due to the presence of second-phase particles as a function of $f / \bar{l}$ is demonstrated in Figure 9(b), where the linear fitting coefficient is $\sim 0.99$. In terms of Figures 9 (a) and (b), the $Q$ value of $5083 \mathrm{Al}$ in the present study can be estimated as $193 \mathrm{~kJ} / \mathrm{mol}$ via extrapolation (solute $\mathrm{Mg}$ concentration $2.93 \mathrm{wt}$ pct in terms of APT measurement in Section III-E, and $f / \bar{l}=1.23 \mu \mathrm{m}^{-1}$ based on the values of $f=3.68 \mathrm{vol} \mathrm{pct}$ and $\bar{l}=30 \mathrm{~nm}$ as presented in Sections III-E and III-A, respectively).

Inspection of the published literature reveals that, during high-temperature deformation, the $\delta$ value of a single-phase Al alloy is primarily determined by deformation conditions (i.e., Zener-Hollomon parameter) and insensitive to the particular alloy compositions ${ }^{[68,91]}$;

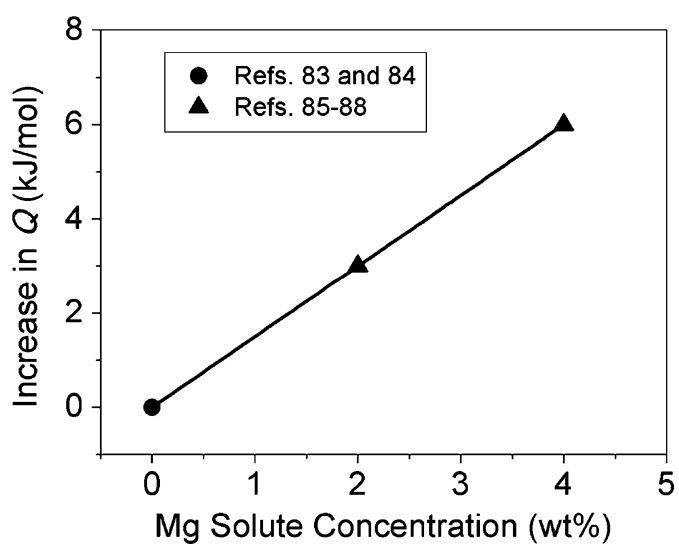

(a)

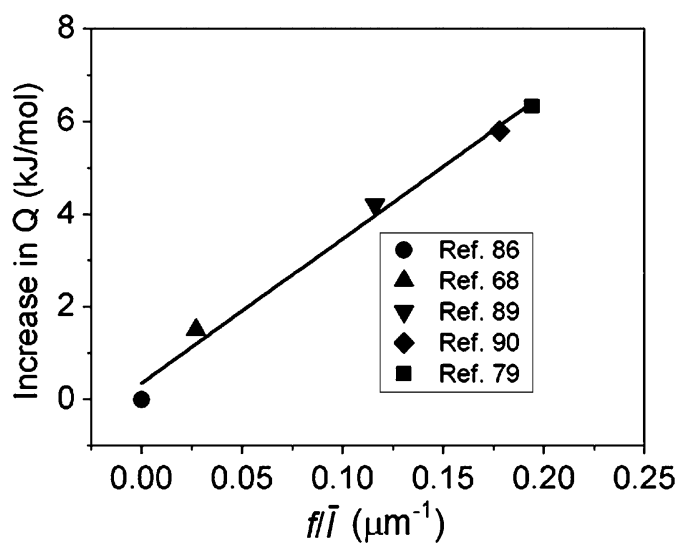

(b)

Fig. 9- (a) the increase in $Q$ as a function of $\mathrm{Mg}$ solute concentration in single-phase $\mathrm{Al}-\mathrm{Mg}$ alloys, and $(b)$ the increase in $Q$ as a function of "particle dispersion level" $(f / \bar{l})$ in $\mathrm{Al}$ alloys. 
however, the $\delta$ value can be effectively reduced in an $\mathrm{Al}$ alloy containing the dispersion of fine second-phase particles. ${ }^{[68]}$ Based on the discussion, it can be presumably suggested that the presence of second-phase particles changes the values of $A$ and $B$ in Eq. [7]. Given that the influence of second-phase particles on DRV and thereby on $\delta$ can be represented by $f / \bar{l}$ as discussed above, $A$ and $B$ can be considered as a function of $f / \bar{l}$. Based on the data of $\delta$ and $Q$ available in the published literature, ${ }^{[68,77,78,90]} \delta$ as a function of $\ln Z$ under a series of $f / \bar{l}$ values is plotted and fitted based on Eq. [7] (i.e., linear fitting) in Figure 10(a), where the plots for a series of $f / \bar{l}$ exhibit an excellent linear fitting coefficient larger than 0.92 . Then, the $A$ and $B$ values obtained based on the fitted lines in Figure 10(a) as a function of $f / \bar{l}$ are demonstrated and linearly fitted in Figure 10(b) with the linear fitting coefficients of 0.91 and 0.90 for $A$ and $B$, respectively. Based on the fitted lines in Figure 10(b), the $A$ and $B$ values corresponding to the $5083 \mathrm{Al}$ in the present study are determined as $A=-7.07273 \mu \mathrm{m}^{-1}$ and $B=0.35857 \mu \mathrm{m}^{-1}$.

Based on $Q=193 \mathrm{~kJ} / \mathrm{mol}, A=-7.07273 \mu \mathrm{m}^{-1}$, and $B=0.35857 \mu \mathrm{m}^{-1}$ as determined above, as well as the processing parameters $\dot{\varepsilon}=0.8 \mathrm{~s}^{-1}$ and $T=673 \mathrm{~K}$, the $\delta$ value of the $5083 \mathrm{Al}$ in the present study is estimated as $157 \mathrm{~nm}$. We then divide the grains in the as-HIPped $5083 \mathrm{Al}$ into two groups: $<157 \mathrm{~nm}$, and 157 to $450 \mathrm{~nm}$ (very few grains $>450 \mathrm{~nm}$ as shown in Figure 1(c)). Purely from a geometrical perspective, the GB spacing of the grains of 157 to $450 \mathrm{~nm}$ can be reduced to less than $\delta=157 \mathrm{~nm}$ during extrusion (the reduction ratio of $\sim 3.2$ in the directions perpendicular to the extrusion direction). However, the GB spacing was simultaneously increased by GB migration. Hence, the actual status for the change of GB spacing, i.e., the likelihood for gDRX to be operative, is determined by the relative magnitude of the rate of lowering GB spacing by extrusion and the rate of widening GB spacing by GB migration. For grains $<157 \mathrm{~nm}$ (less than $\delta$ ), our results suggest that it is unlikely that subgrains are produced inside $5083 \mathrm{Al}$ grains during extrusion. As a consequence of the absence of SGBs inside grains, the pinning pressure to local movement and impingement of HAGBs should be minimized. In a more recent MD investigation of plastic deformation of NS Al at high temperature, ${ }^{[17]}$ it was demonstrated that, during compression to the strain of 21 pct, the one serrated GB segment of a grain that contains no subgrains meets another GB segment on the opposite side of the grain, triggering gDRX. In the present study, however, the possibility for gDRX to be active in the grains $<157 \mathrm{~nm}$ is still determined by the relative magnitude of the rate of reducing GB spacing by extrusion and the rate of increasing GB spacing by GB migration, as discussed above.

Next, the possibility for grain rotation to occur during hot extrusion is examined as follows. Generally, two mechanisms are responsible for the formation of a subgrain structure during plastic deformation: (1) DRV and (2) rotation and incomplete coalescence of grains with HAGBs, i.e., leaving low-angle SGBs between the prior grains with HAGBs. In the extruded $5083 \mathrm{Al}$,

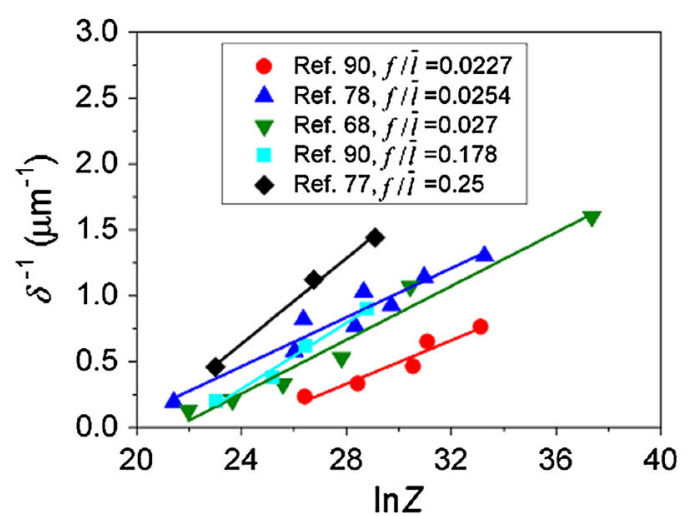

(a)

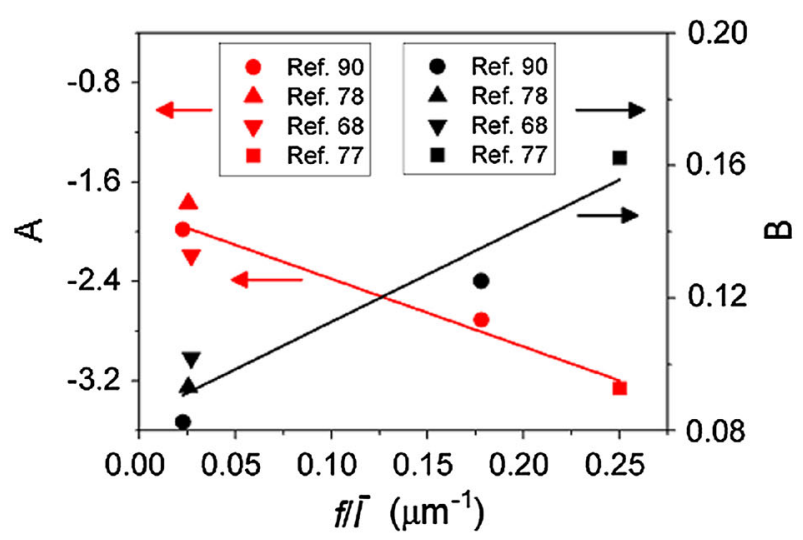

(b)

Fig. $10-(a) \delta^{-1}$ as a function of $\ln Z$ in a series of $\mathrm{Al}$ alloys with different $f / \bar{l}$, where the data points correspond to the line with the same colors, and (b) $A$ and $B$ as a function of $f / \bar{l}$, where the red and black data points represent values for $\mathrm{A}$ and $\mathrm{B}$, respectively (Color figure online).

subgrains of $\sim 450$ to $\sim 1000 \mathrm{~nm}$ in size have been observed (Figure 5(a)), which are much larger than those formed via $\operatorname{DRV}(\delta=157 \mathrm{~nm})$. It is then argued that such a grain comprising subgrains of $\sim 450$ to $\sim 1000 \mathrm{~nm}$ in size may originate from rotation and incomplete coalescence of a few prior grains that were initially separated by HAGBs. These grains with HAGBs come from either the original grains in the as-HIPped $5083 \mathrm{Al}$ or the grains after GB migration of the original grains. For these grains, plastic deformation was primarily accommodated by grain sliding and rotation, whereas intragranular dislocation activity may have been weakened and consequently, the magnitude of strain used to induce intragranular dislocation activity is insufficient to develop subgrain structure inside these grains. It is noted that the dark grain in Figure 6 is characterized by the absence of subgrain structure at the entire GI. One of the possible mechanisms responsible for the formation of such a grain may be the rotation and complete coalescence of the prior grains with HAGBs.

The microstructural evolution inside the grain as shown in Figure 4(a) may be primarily attributable to GB migration. As a site for relaxation of dislocation strain energy, GBs behave as sinks for dislocation 
absorption. ${ }^{[92,93]}$ When GB migration occurred, transgranular movement of HAGBs induced an extensive interaction between these HAGBs and the dislocations, leading to a significant decrease in dislocation density; however, subsequent straining would increase the dislocation density again. The regions that were swept by HAGBs in the earlier stage may undergo a magnitude of subsequent strain, which is higher than the critical strain corresponding to the onset of the steady state, leading to the formation of well-defined subgrain structure via DRV in the regions as marked by "SG" in Figure 4(a). The sizes of these subgrains fall in the range from 100 to $300 \mathrm{~nm}$ as analyzed in Section III-C, similar to the subgrain size produced by DRV (i.e., $\delta=157 \mathrm{~nm}$ ). In contrast, the regions that were swept by HAGBs in the later stage may be subjected to a relatively low magnitude of subsequent strain, which is insufficiently high to develop subgrain structure in the regions as marked by "D" in Figure 4(a).

On the basis of the aforementioned discussion, the mechanisms underlying the microstructural evolution associated with HAGB motion during hot extrusion include GB migration, grain rotation, and possible gDRX. GB migration and grain rotation were responsible for grain growth, while gDRX led to possible grain refinement. The final grain size in the extruded $5083 \mathrm{Al}$ indicates that GB migration and grain rotation played a dominant role, leading to overall grain growth. Despite the strong resistance forces generated by the secondphase particles and the solutes segregated at GBs, which even almost inhibited GB migration and grain rotation during annealing at $673 \mathrm{~K}\left(400^{\circ} \mathrm{C}\right)$ as reported in Section III-B, the introduction of externally applied stresses during hot extrusion may overcome these resistance forces, enabling the operation of GB migration and grain rotation. Given that both stress-induced GB migration and grain rotation were operative during extrusion, it is difficult to reveal the effect of secondphase particles and solute segregation at GBs on the two mechanisms separately via experiments. In order to solve this problem, we have formulated a theoretical framework that can be implemented to quantify the effect of second-phase particles and solute segregation at GBs on the two mechanisms. This analytical model is described in detail elsewhere. ${ }^{[94]}$

\section{CONCLUSIONS}

1. The results in the present study indicate that, in an UFG 5083Al containing second-phase particles and solutes segregated at GBs, grain growth was essentially inhibited during annealing at $673 \mathrm{~K}\left(400^{\circ} \mathrm{C}\right)$ for a prolonged period of 5 hours in absence of an externally applied stress; in contrast, grain growth by a factor of $\sim 2.7$ occurred during extrusion at $673 \mathrm{~K}$ $\left(400{ }^{\circ} \mathrm{C}\right)$. The significant grain growth during hot extrusion can be attributed to the externally applied stresses coming from the state of stress imposed during extrusion.

2. The mechanisms underlying the microstructural evolution related to HAGBs during hot extrusion involved GB migration, grain rotation, and possible gDRX while dDRX did not appear to occur. GB migration and grain rotation contributed to stressinduced grain growth, and simultaneously possible gDRX led to grain refinement. Our results suggests that GB migration and grain rotation dominate, resulting in overall grain growth. Although the strong resistance forces were generated by the second-phase particles and the solutes segregated at GBs, the exertion of externally applied stresses can overcome these resistance forces, enabling the operation of GB migration and grain rotation.

\section{ACKNOWLEDGMENTS}

This work was supported by the U. S. Office of Naval Research N00014-09-1-0437. Y.J. Lin acknowledges the financial support from the One Hundred Talents Project of Hebei Province, China and the Research Program of Department of Education, Hebei Province, China (Project No. ZH2011111). The authors also thank George E. Kim with the Perpetual Technologies (Montreal, Canada) for providing mechanically milled 5083 Al powders. Prof. David N. Seidman and Dr. Dieter Isheim are acknowledged for providing access to atom probe and other facilities at Northwestern University Center for Atom Probe Tomography (NUCAPT).

\section{APPENDIX}

The calculation of enthalpy of segregation using firstprinciples simulations

Enthalpy of segregation $\left(H_{\mathrm{seg}, \mathrm{i}}\right)$ is defined as the difference in the total enthalpies of a system with solute atoms of a specific element $i$ at GIs $\left(H_{i}^{\mathrm{GI}}\right)$ and at GBs $\left(H_{i}^{\mathrm{GB}}\right)$, i.e., $H_{\mathrm{seg}, i}=H_{i}^{\mathrm{GI}}-H_{i}^{\mathrm{GB}}$. Thus, $H_{\mathrm{seg}, i}$ can be considered to be temperature independent if neglecting the difference in specific heat between the solute atoms at GIs and at GBs. Given that $H_{i}^{G I}=E_{i}^{\mathrm{GI}}-P V_{i}^{\mathrm{GI}}$ and $H_{i}^{\mathrm{GB}}=E_{i}^{\mathrm{GB}}-P V_{i}^{\mathrm{GB}}$ (where $E_{i}^{\mathrm{GI}}$ and $E_{i}^{\mathrm{GB}}$ are the total energies of a system with solute atoms of a specific element $i$ at GIs and GBs, respectively, $V_{i}^{\mathrm{GI}}$ and $V_{i}^{\mathrm{GB}}$ are the volumes of a system with solute atoms of a specific element $i$ at GIs and GBs, respectively, and $P$ is the pressure of the system), if one neglects the difference in the volumes between the solute atoms at GIs and at GBs (i.e., $\left.\quad V_{i}^{\mathrm{GI}}=V_{i}^{\mathrm{GB}}\right)$, then $E_{\mathrm{seg}, i}=E_{i}^{\mathrm{GI}}-E_{i}^{\mathrm{GB}}=H_{\mathrm{seg}, i}$, where $E_{\mathrm{seg}, i}$ is defined as the energy of segregation. In the present study, $H_{\mathrm{seg}, i}$ is determined by calculating $E_{\mathrm{seg}, i}$ at $0 \mathrm{~K}$ via first-principles simulations. The details of calculations are described as follows.

As a typical HAGB in Al, symmetrical tilt $\Sigma 5$ (012) [100] GB has been extensively studied by experimen$\operatorname{tal}^{[95,96]}$ and theoretical ${ }^{[97,98]}$ investigations. Hence, it was selected to represent the general HAGBs in the present study. The GB structure was simulated using a supercell that was repeated periodically in the threedimensions to reproduce the entire crystal lattice studied 


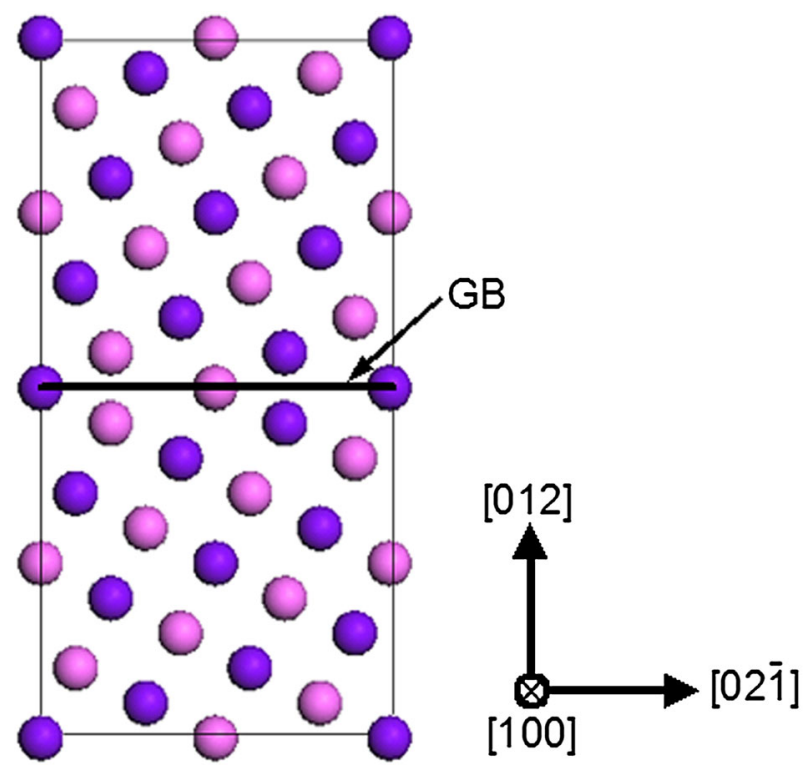

Fig. A1-The 40-atom supercell that contains a symmetrical tilt $\Sigma 5$ (012) [100] GB, together with the crystallography in the supercell, where the GB is marked by a solid line and the atoms located in different planes along [100] direction are denoted by balls with different colors (Color figure online).

(namely "periodical boundary conditions"). Figure A1 shows the supercell of 40 atoms used in the present study, as well as the crystallography involved. The supercell includes two identical grains, and each of the two grains contains eleven (012) atomic layers with one layer shared by the two grains, which represents the GB as indicated by the solid line in Figure A1. When the total energies of the supercell with solute atoms at the GIs and at the GBs were calculated to acquire the energy of segregation, the solute atoms replaced the positions of $\mathrm{Al}$ atoms in the lattice at the GIs and at the $\mathrm{GB}$ for $\mathrm{Mg}, \mathrm{Mn}, \mathrm{Cr}, \mathrm{Fe}, \mathrm{Ni}, \mathrm{Si}$, and $\mathrm{Cu}$, but were inserted in the interstitial sites of the Al lattice for $\mathrm{C}, \mathrm{O}$, and $\mathrm{N}$.

The first-principles simulations were conducted within the framework of density functional theory (DFT), as implemented in the CASTEP code (Cambridge Serial Total Energy Package). ${ }^{[99]}$ The ion-electron interactions were modeled by the ultrasoft pseudopotential method. ${ }^{[100]}$ The exchange and correlation interaction was described by the generalized gradient approximation (GGA) with the Perdew-Burke-Ernzerhof (PBE) parameterization. ${ }^{[101,102]}$ Plane wave cutoff energies of 310, 250, 290, 280, 270, 180, 270, 240, 300, and $220 \mathrm{eV}$ were set for $\mathrm{Mg}, \mathrm{Mn}, \mathrm{Cr}, \mathrm{Fe}, \mathrm{Ni}, \mathrm{Si}, \mathrm{Cu}, \mathrm{C}, \mathrm{O}$, and $\mathrm{N}$, respectively. The Brillouin zone integrations were performed using a Monkhorst-Pack $k$-point, ${ }^{[103]}$ and the $k$-point mesh was sampled by $5 \times 2 \times 1$ for the supercell used herein. The optimized lattice constant for bulk Al at $0 \mathrm{~K}(4.05 \AA)$ is well consistent with the experimental data at $20 \mathrm{~K}(4.03$ $\AA)^{[104]}$ and other simulated result $(4.05 \AA) .{ }^{[97]}$ The total energy was converged numerically to $2 \times 10^{-6} \mathrm{eV} /$ atom with respect to electronic, ionic, and unit cell degrees of freedom.

\section{REFERENCES}

1. T.J. Rupert, D.S. Gianola, Y. Gan, and K.J. Hemker: Science, 2009 , vol. 326, pp. 1686-90.

2. F. Mompiou, D. Caillard, and M. Legros: Acta Mater., 2009, vol. 57, pp. 2198-209.

3. P. Liu, S.C. Mao, L.H. Wang, X.D. Han, and Z. Zhang: Scripta Mater., 2011, vol. 64, pp. 343-46.

4. Z.W. Shan, E.A. Stach, J.M.K. Wiezorek, J.A. Knapp, D.M. Follstaedt, and S.X. Mao: Science, 2004, vol. 305, pp. 654-57.

5. Y.B. Wang, B.Q. Li, M.L. Sui, and S.X. Mao: Appl. Phys. Lett., 2008, vol. 92, p. 011903.

6. M. Jin, A.M. Minor, E.A. Stach, and J.W. Morris: Acta Mater., 2004, vol. 52, pp. 5381-87.

7. M. Legros, D. Gianola, and K. Hemker: Acta Mater., 2008, vol. 56, pp. $3380-93$.

8. F. Mompiou, M. Legros, and D. Caillard: J. Mater. Sci., 2011, vol. 46, pp. 4308-13.

9. X.Z. Liao, A.R. Kilmametov, R.Z. Valiev, H.S. Gao, X.D. Li, A.K. Mukherjee, J.F. Bingert, and Y.T. Zhu: Appl. Phys. Lett., 2006, vol. 88, p. 021909.

10. K. Zhang, J.R. Weertman, and J.A. Eastman: Appl. Phys. Lett., 2005, vol. 87, p. 061921.

11. G.J. Fan, L.F. Fu, H. Choo, P.K. Liaw, and N.D. Browning: Acta Mater., 2006, vol. 54, pp. 4781-92.

12. H.M. Wen, Y.H. Zhao, Y. Li, O. Ertorer, K.M. Nesterov, R.K. Islamgaliev, R.Z. Valiev, and E.J. Lavernia: Philos. Mag., 2010, vol. 90 , pp. $4541-50$.

13. H.M. Wen, R.K. Islamgaliev, K.M. Nesterov, R.Z. Valiev, and E.J. Lavernia: Philos. Mag. Lett., 2013, vol. 93, pp. 481-89.

14. D.A. Molodov, V.A. Ivanov, and G. Gottstein: Acta Mater., 2007, vol. 55, pp. 1843-48.

15. D.A. Molodov, T. Gorkaya, and G. Gottstein: J. Mater. Sci., 2011, vol. 46, pp. 4318-26.

16. A.J. Haslam, D. Moldovan, V. Yamakov, D. Wolf, S.R. Phillpot, and H. Gleiter: Acta Mater., 2003, vol. 51, pp. 2097-112.

17. A.P. Gerlich, L. Yue, P.F. Mendez, and H. Zhang: Acta Mater., 2010, vol. 58, pp. 2176-85.

18. J. Monk and D. Farkas: Phys. Rev. B, 2007, vol. 75, p. 045414.

19. J. Schiøtz: Mater. Sci. Eng. A, 2004, vols. 375-377, pp. 975-79.

20. F. Sansoz and V. Dupont: Appl. Phys. Lett., 2006, vol. 89, p. 111901.

21. V.A. Ivanov and Y. Mishin: Phys. Rev. B, 2008, vol. 78, p. 064106.

22. J.W. Cahn, Y. Mishin, and A. Suzuki: Acta Mater., 2006, vol. 54, pp. 4953-75.

23. Z.T. Trautt and Y. Mishin: Acta Mater., 2012, vol. 60, pp. 240724.

24. A. Elsener, O. Politano, P.M. Derlet, and H. Van Swygenhoven : Acta Mater., 2009, vol. 57, pp. 1988-2001.

25. J.R. Davis: Aluminum and Aluminum Alloys, ASM International, Materials Park, OH, 1993.

26. J.R. Davis: Carbon and Alloy Steels, ASM International, Materials Park, OH, 1996.

27. R.Z. Valiev and T.G. Langdon: Prog. Mater Sci., 2006, vol. 51, pp. 881-981.

28. A.P. Zhilyaev and T.G. Langdon: Prog. Mater Sci., 2008, vol. 53, pp. 893-979.

29. Y. Saito, H. Utsunomiya, N. Tsuji, and T. Sakai: Acta Mater., 1999, vol. 47, pp. 579-83.

30. D.B. Witkin and E.J. Lavernia: Prog. Mater. Sci., 2006, vol. 51, pp. $1-60$.

31. J.W. Cahn and J.E. Taylor: Acta Mater., 2004, vol. 52, pp. 4887-98.

32. G.J. Fan, L.F. Fu, Y.D. Wang, Y. Ren, H. Choo, P.K. Liaw, G.Y. Wang, and N.D. Browning: Appl. Phys. Lett., 2006, vol. 89, p. 101918.

33. S. Brandstetter, K. Zhang, A. Escuadro, J.R. Weertman, and H. Van Swygenhoven : Scripta Mater., 2008, vol. 58, pp. 61-64.

34. F. Tang, D.S. Gianola, M.P. Moody, K.J. Hemker, and J.M. Cairney: Acta Mater., 2012, vol. 60, pp. 1038-47.

35. S. Zhang, W. Hu, R. Berghammer, and G. Gottstein: Acta Mater., 2010, vol. 58, pp. 6695-6705.

36. Y.H. Zhao, X.Z. Liao, Z. Jin, R.Z. Valiev, and Y.T. Zhu: Acta Mater., 2004, vol. 52, pp. 4589-99. 
37. B.Q. Han, Z. Lee, S.R. Nutt, E.J. Lavernia, and F.A. Mohamed: Metall. Mater. Trans. A, 2003, vol. 34A, pp. 603-13.

38. D. Witkin, B.Q. Han, and E.J. Lavernia: J. Mater. Res., 2005, vol. 20, pp. 2117-26.

39. G. Lucadamoa, N.Y.C. Yang, C. San Marchi, and E.J. Lavernia: Mater. Sci. Eng. A, 2006, vol. 430, pp. 230-41.

40. T.B. Massalski: Binary Alloy Phase Diagrams, 2nd ed., ASM International, Materials Park, OH, 1990.

41. Y. Du, Y.A. Chang, B.Y. Huang, W.P. Gong, Z.P. Jin, H.H. Xu, Z.H. Yuan, Y. Liu, Y.H. He, and F.Y. Xie: Mater. Sci. Eng. A, 2003, vol. 363, pp. 140-51.

42. S.C. Khatri, A. Lawley, M.J. Koczak, and K.G. Grassett: Mater. Sci. Eng. A, 1993, vol. 167, pp. 11-21.

43. F. Carreno and O.A. Ruano: Acta Mater., 1998, vol. 46, pp. 159-67.

44. Y.B. Wang, J.C. Ho, X.Z. Liao, H.Q. Li, S.P. Ringer, and Y.T. Zhu: Appl. Phys. Lett., 2009, vol. 94, p. 011908.

45. S. Ni, Y.B. Wang, X.Z. Liao, S.N. Alhajeri, H.Q. Li, Y.H. Zhao, E.J. Lavernia, S.P. Ringer, T.G. Langdon, and Y.T. Zhu: Scripta Mater., 2011, vol. 64, pp. 327-30.

46. S. Cheng, Y.H. Zhao, Y.T. Zhu, and E. Ma: Acta Mater., 2007, vol. 55 , pp. 5822-32.

47. F.K. Lotgering: J. Inorg. Nucl. Chem., 1959, vol. 9, pp. 113-23.

48. Powder diffraction file, No. 04-0787, Joint Committee on Powder Diffraction Standards (JCPDS), Swarthmore, PA, 1990

49. Y.S. Park, K.H. Chung, N.J. Kim, and E.J. Lavernia: Mater. Sci. Eng. A, 2004, vol. 374, pp. 211-16.

50. H.P. Klug and L. Alexander: X-Ray Diffraction Procedures for Polycrystalline and Amorphous Materials, 2nd ed., Wiley, New York, 1974.

51. G.K. Williamson and R.E. Smallman: Philos. Mag., 1956, vol. 1, pp. 34- 46 .

52. R.E. Smallman and K.H. Westmacott: Philos. Mag., 1957, vol. 2, pp. 669-83.

53. P. Lejcek: Grain Boundary Segregation in Metals, Springer, Berlin, 2010.

54. P.C. Millett, R.P. Selvam, and A. Saxena: Acta Mater., 2007, vol. 55 , pp. 2329-36.

55. F. Liu and R. Kirchheim: Scripta Mater., 2004, vol. 51, pp. 521-25.

56. R. Kirchheim: Acta Mater., 2002, vol. 50, pp. 413-19.

57. X.Z. Liao, J.Y. Huang, Y.T. Zhu, F. Zhou, and E.J. Lavernia: Philos. Mag., 2003, vol. 83, pp. 3065-75.

58. M.A. Meyers, A. Mishra, and D.J. Benson: Prog. Mater Sci., 2006, vol. 51, pp. 427-556.

59. D. Wolf: Scripta Metall., 1989, vol. 23, pp. 1713-18.

60. A.J. Haslam, S.R. Phillpot, D. Wolf, D. Moldovan, and H. Gleiter: Mater. Sci. Eng. A, 2001, vol. 318, pp. 293-312.

61. J.P. Hirth and J. Lothe: Theory of Dislocations, 2nd ed., Wiley, New York, 1982.

62. T. Gorecki: Mater. Sci. Eng., 1980, vol. 43, pp. 225-30.

63. P. Yavari, F.A. Mohamed, and T.G. Langdon: Acta Metall., 1981, vol. 29, pp. 1495-507.

64. F.J. Humphreys and M. Hatherly: Recrystallization and Related Annealing Phenomena, 2nd ed., Elsevier, Boston, MA, 2004.

65. G. Gottstein and L.S. Shvindlerman: Grain Boundary Migration in Metals, 2nd ed., Taylor \& Francis, Boca Raton, FL, 2010.

66. K.E. Harris, V.V. Singh, and A.H. King: Acta Mater., 1998, vol. 46, pp. 2623-33.

67. F.J. Humphreys: Acta Mater., 1997, vol. 45, pp. 5031-39.

68. A. Gholinia, F.J. Humphreys, and P.B. Prangnell: Acta Mater., 2002, vol. 50, pp. 4461-76.

69. H. Jazaeri and F.J. Humphreys: Acta Mater., 2004, vol. 52, pp. 3251-62.

70. S. Gourdet and F. Montheillet: Mater. Sci. Eng. A, 2000, vol. 283, pp. 274-88.

71. G.E. Dieter: Mechanical Metallurgy, McGraw-Hill Book Company, New York, 1986.
72. H. Hu: Texture, 1974, vol. 1, pp. 233-58.

73. H.E. Vatne and A. Johansen: Mater. Sci. Forum, 1998, vols. $273-$ 275 , pp. $397-402$.

74. S. Kaneko, K. Murakami, and T. Sakai: Mater. Sci. Eng. A, 2009 , vol. 500, pp. 8-15.

75. H. Inoue and T. Takasugi: Mater. Trans., 2007, vol. 48, pp. 2014 22.

76. P.B. Prangnell, J.R. Bowen, and P.J. Apps: Mater. Sci. Eng. A, 2004, vols. 375-377, pp. 178-185.

77. A. Gholinia, F.J. Humphreys, and P.B. Prangnell: Mater. Sci. Technol., 2000, vol. 16, pp. 1251-55.

78. W. Blum, Q. Zhu, R. Merkel, and H.J. McQueen: Mater. Sci. Eng. A, 1996, vol. 205, pp. 23-30.

79. H.J. McQueen, E. Evangelista, J. Bowles, and G. Crawford: Met. Sci., 1984, vol. 18, pp. 395-402.

80. X. Duan and T. Sheppard: Mater. Sci. Eng. A, 2003, vol. 351, pp. 282-92.

81. C. Zener and J.H. Hollomon: J. Appl. Phys., 1944, vol. 15, pp. 22-26.

82. S. Spigarelli, E. Evangelista, and H.J. McQueen: Scripta Mater., 2003, vol. 49, pp. 179-83.

83. H.J. McQueen, W.A. Wong, and J.J. Jonas: Can. J. Phys., 1967, vol. 45 , pp. $1225-35$.

84. M.M. Farag and C.M. Sellars: J. Inst. Met., 1973, vol. 101, pp. $137-45$.

85. A. Plumtree and G. Deep: Met. Technol., 1977, vol. 4, pp. 1-5.

86. M. Raghaven and E. Shapiro: Metall. Trans. A, 1980, vol. 11A, pp. 117-21.

87. R.A. Ayres: Metall. Trans. A, 1979, vol. 10A, pp. 849-54.

88. M.A. Zaidi and T. Sheppard: Met. Sci., 1982, vol. 16, pp. 229-38.

89. H.E. Vatne, R. Shahanf, and E. Nes: Acta Mater., 1996, vol. 44, pp. 4447-62.

90. F. Furu, R. Orsund, and E. Nes: Mater. Sci. Eng. A, 1996, vol. 214 , pp. $122-32$.

91. T. Furu, K. Marthinsen, and E. Nes: in Proceedings of Recrystallisation, M. Fuentes and J.G. Sevillano, eds., San Sebastian, Spain, 1992.

92. D.A. Molodov, L.S. Shvindlerman, and G. Gottstein: Z. Metallkd., 2003, vol. 94, pp. 1117-26.

93. C.E. Carlton and P.J. Ferreira: Acta Mater., 2007, vol. 55, pp. 3749-56.

94. Y.J. Lin, H.M. Wen, Y. Li, B. Wen, W. Liu, and E.J. Lavernia: Unpublished research, 2014.

95. R. Gronsky and P. Furrer: Metall. Trans. A, 1981, vol. 12A, pp. $121-27$.

96. S.H. Kim, U. Erb, K.T. Aust, and G. Palumbo: Scripta Mater., 2001, vol. 44, pp. 835-39.

97. V.I. Razumovskiy, A.V. Ruban, I.M. Razumovskii, A.Y. Lozovoi, V.N. Butrimb, and Y.K. Vekilov: Scripta Mater., 2011, vol. 65 , pp. 926-29.

98. S.J. Zhang, O.Y. Kontsevoi, A.J. Freeman, and G.B. Olson: Acta Mater., 2011, vol. 59, pp. 6155-67.

99. M.D. Segall, P.J.D. Lindan, M.J. Probert, C.J. Pickard, P.J. Hasnip, S.J. Clark, and M.C. Payne: J. Phys. Condens. Mater., 2002 , vol. 14 , pp. 2717-44.

100. D.R. Hamann, M. Schluter, and C. Chiang: Phys. Rev. Lett., 1979, vol. 43, pp. 1494-97.

101. M.C. Payne, M.P. Teter, D.C. Allan, T.A. Arias, and J.D. Joannopoulos: Rev. Mod. Phys., 1992, vol. 64, pp. 1045-97.

102. J.P. Perdew, K. Burke, and M. Ernzerhof: Phys. Rev. Lett., 1996, vol. 77 , pp. $3865-68$.

103. H.J. Monkhorst and J.D. Pack: Phys. Rev. B, 1976, vol. 13, pp. 5188-92.

104. M.E. Starumanis and C.L. Woodward: Acta Crystallogr. A, 1971, vol. 27 , pp. $549-51$. 